Portland State University

PDXScholar

10-30-1997

\title{
Whole Body i=In Vivo Vascular Compliance in Two Amphibians, Bufo Marinus and Rana Cate
}

Todd Micheal Hoagland

Portland State University

Follow this and additional works at: https://pdxscholar.library.pdx.edu/open_access_etds

Part of the Animal Sciences Commons, Biology Commons, and the Systems and Integrative Physiology Commons

Let us know how access to this document benefits you.

\section{Recommended Citation}

Hoagland, Todd Micheal, "Whole Body i=In Vivo Vascular Compliance in Two Amphibians, Bufo Marinus and Rana Cate" (1997). Dissertations and Theses. Paper 5382.

https://doi.org/10.15760/etd.7255

This Thesis is brought to you for free and open access. It has been accepted for inclusion in Dissertations and Theses by an authorized administrator of PDXScholar. Please contact us if we can make this document more accessible: pdxscholar@pdx.edu. 


\section{ABSTRACT}

An abstract of the thesis of Tamera Ann Hart-Johnson for the Master of Science in Psychology presented June 2,1997 .

Title: Pregnancy Outcomes: A Study Testing a Model for Predicting Health Outcomes in Pregnancy.

There is a persistent relationship between socioeconomic status and physical health outcomes found in the literature; however the variables mediating this relationship are many, and ways that they interact with each other are complex. The goal of understanding this relationship is to decrease the disparity in health by socioeconomic status.

This study tested a biopsychosocial model proposed by David Williams (1990) to explain the relationship between socioeconomic status and physical health outcomes. The model included the following latent factors: demographics, socioeconomic status, biomedical risk, medical care, psychosocial variables, and health outcomes. The model was tested through a secondary data analysis. 
The 1937 women who participated entered one of six Portland area clinics over a three year period for prenatal care. Data was collected over three time points; two interviewsdone during the pregnancy and birth outcome data, taken from medical records. There were 1134 women with complete data for the purpose of this analysis.

Confirmatory factor analysis was used to verify that the measurement tools fit the measurement model for the latent factors. After dropping four of the 28 measures, the fit was adequate and covariance structure modelling was used to test the structural model proposed by Williams. The fit of the model was adequate, however, only $3.8 \%$ of the variance in the outcomes measures was explained by the model, and three of the five paths leading to outcomes were insignificant.

An alternative model with psychosocial variables broken into the two factors of psychosocial resources and behaviors was also tested with similar results. The variance explained in outcomes was $4.3 \%$ and the only factors with paths significantly related to outcomes were demographics and biomedical risk.

It is of note in both models that SES was a very powerful predictor of the medical care variable, 
predicting over $50 \%$ of its variance. The psychosocial variable also had $20.7 \%$ and $18.8 \%$ of its variance explained by the preceding factors in Williams' model and the alternative model respectively.

Since the model did fit the data, it is believed improvements in utility of the model could be seen if a study was designed specifically for testing this model. 
PREGNANCY OUTCOMES: A STUDY TESTING A MODEL FOR PREDICTING HEALTH OUTCOMES IN PREGNANCY

$$
\text { by }
$$

TAMERA ANN HART-JOHNSON

A thesis submitted in partial fulfillment of the requirements for the degree of

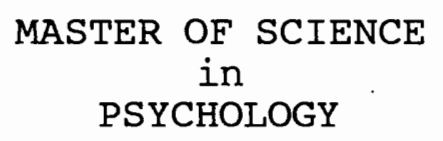

Portland State University 1997 
Pregnancy Outcomes

\section{Table of Contents}

I.

Title Page

II.

Table of Contents

2

III.

List of Tables

IV.

List of Figures

V.

Introduction

- The Relationship 6

- Predictors of Health Outcomes 10 in Williams' Model

- The Interrelationship Among Variables in Williams' Model Model

The Model and Pregnancy 23

Research Overview 28

Research Hypotheses $\quad 32$

VI. Method

Subjects

Data Collection $\quad 38$

Specific Tools as Used in the 39 Current Study

VII. Results 
Covariance Structure Model

Test for Williams' Model

The Alternative Model

Regressions

VIII. Discussion
Descriptive Information
Test of the Measurement Model 79
Test of Williams' Model
Alternative Model
Hierarchical Regressions
Testing the Relationship of the Psychosocial Measures to the Outcomes Measures
- Limitations of this study
Summary and Conclusions

IX.

References

$\mathrm{X}$.

Appendix

Appendix A: Time 1

Data Collection

Appendix B: Time 2

Data Collection

Appendix C: Time 3

Data Collection 


\section{List of Tables}

1. Measures and the Latent Factors they Indicate 34

2. Sociodemographic Descriptive Information 49

3. Correlations of the Psychosocial Variables 53 Time 1 and Time 2

4. Inter-correlations of the Psychosocial 54 Variables

5. Outcomes Statistics 56

6. Measurement Model: Confirmatory Factor 57 Analysis

7. Factor Loadings for the Measurement Variables 63

8. Lambda Loadings for the Measurement Model 65

9. Factor Loadings for the Alternative 70 Measurement Model

10. Regression for Birthweight 73

11. Regression for 5-Minute Apgar 74

12. Regression for Gestational Age 75

13. Regression for Infant Complications 76 
Pregnancy Outcomes

\section{List of Figures}

1. Williams' Model

2. Proposed Model

3. Model with Path Coefficients and t-values

4. Alternative Model with Path Coefficients and 68 $t$-Values 


\section{Pregnancy Outcomes: A Study}

\section{Testing a Model for Predicting}

\section{Health Outcomes in Pregnancy}

The social sciences have often studied differences in access to desirable resources based on socioeconomic status. One of the differences studied has been the better health of people in higher socioeconomic groups. Historically, people of lower social status have suffered greater morbidity and earlier mortality than people of higher status (Williams, 1990). Williams suggests that this is tied to the social structure and uses social structure and personality theory to make this argument. Social structure and personality theory suggest that lifestyle characteristics and living conditions are patterned responses to the social structure.

Three things occurred over the last forty years that should have systematically equalized health by social status: infectious diseases declined as a major factor producing mortality; adequate nutrition, housing, water, and waste disposal became available to most families in the United States; and Medicare and Medicaid placed medical treatment within reach for most poor people. Yet, the disparity in health persists. A review by Antonovsky (1967) showed that while the 
mortality gap by SES narrowed through the 1940 's, it quit doing so in the $50^{\prime} \mathrm{s}$ and $60^{\prime} \mathrm{s}$. Another study found that the difference by SES in health actually increased between 1960 and 1986 (Pappas, Queen, Hadden, \& Fisher, 1993). So the relationship between SES and health appears to be based on more than differences in physical environment and access to medical care.

House, Kessler, and Herzog (1990) pointed out one unfortunate outcome of the strides that have been made in health care. By pushing back the age of mortality for all, but the age of morbidity only for the more advantaged, the differences in health by SES increase. The period of suffering for the advantaged SES groups decreases while for the disadvantaged groups it increases.

\section{The Relationship}

williams (1990) asserts that there are psychosocial factors systematically affected by the social structure, which in turn affect physical health; he employs a model to explain the relationship (Figure 1). In this model demographics affect SES and the biomedical factor. For example, women tend to be poorer and also have different health problems than men. SES and the biomedical factor are correlated, as the previous example would imply. Demographics also 
Pregnancy Outcomes

Figure 1: Williams Model

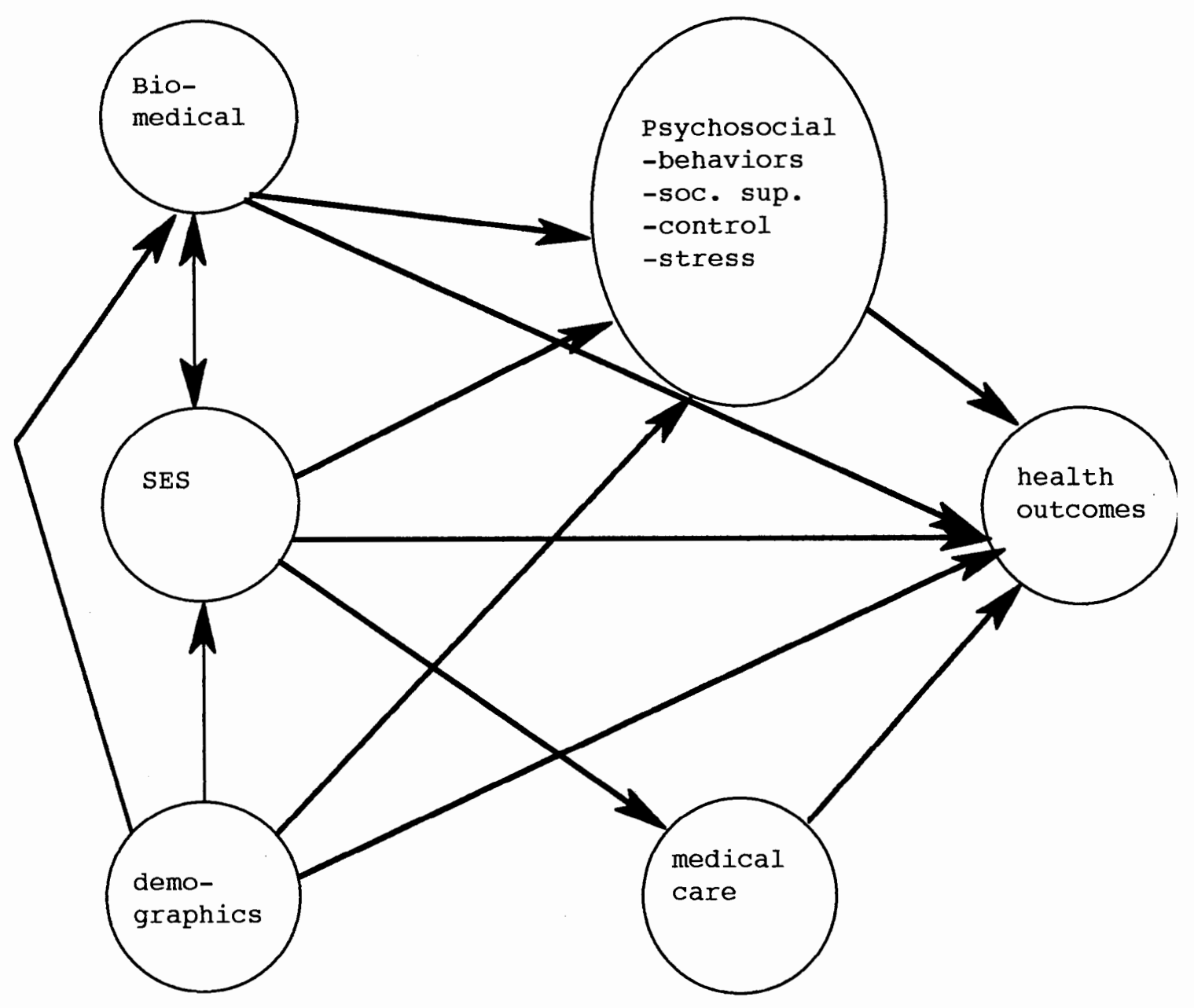


affect psychosocial variables and health outcomes directly. For example, minorities have different stressors than Non-Hispanic white people, and older people are prone to poorer health. The biomedical factor affects the psychosocial factor and also health outcomes. This can be seen in a person who has a health problem which limits mobility and therefore access to social networks. This person may also have a greater predisposition to other health problems because of his existing health condition.

Socioeconomic status affects the psychosocial factor, medical care, and health outcomes. Poorer people tend to have fewer psychosocial resources such as social support, poorer quality of medical care, and poorer health. Psychosocial factors and medical care both affect health outcomes. Williams also believes in indirect effects on health of SES through the psychosocial factor and medical care.

According to Allison (1991) this shift in thinking is important. Psychosocial patterns are viewed here not as individual characteristics, but as patterned responses to the social structure. In the 1970's there was a shift in policy in the United States, holding individuals responsible for their own health, and minimizing the role of the social and physical 
environment in which individual behaviors take place. However, Williams' model is an example of a return to examining social systems and their impact on health. Allison warned however against blaming the system, as there are many things individuals could do to influence their health.

The Predictors of Health Outcomes in Williams' Model Demographics

Demographic variables in Williams' model are those which are unalterable. He conceptualizes the demographic factor to include sex, age, and race.

SES

Socioeconomic status is not so easily conceptualized. It includes the descriptive characteristics which over a lifetime are alterable, but which tend to hold us in a general social pattern (social class) based on the relationship these variables have to each other and other factors. SES is usually conceptualized as education, income, and occupation because these are objective, distinctive variables which tend to be related to the broader concept of "class".

The Biomedical Factor

Biomedical variables are those early environmental, genetic, and constitutional variables that people bring 
into their current health status. Environmental variables would include such things as carcinogens or viruses to which a person has been exposed. Genetic variables have to do with inherited predispositions. Constitutional variables include such things as the functioning of the immune system and the general health of a person.

\section{Medical Care}

Medical care is the access, quality, and quantity of medical care people use.

The Psychosocial Factor

Psychosocial variables are numerous, but those discussed by williams as related to health are health practices, social ties, perceptions of control, and stress. Discussing these variables as a single psychosocial factor raises some questions. These difficulties will be discussed later.

\section{Health outcomes}

Health outcomes are the state of health or disease a person is in at the point of measurement.

\section{The Interrelationship among the Variables}

\section{in Williams' Model}

\section{Demographics and SES}

The literature provides support for the various paths outlined in Williams' model. Belle (1990) 
supports the relationship of demographics affecting SES. She notes that poverty is growing fastest among women and children, with minorities being the most vulnerable.

There is also evidence that demographics and SES affect health. House et al. (1990) found that women, non-whites, older people, less educated people, poorer people, and non-married people are generally less healthy than men, whites, younger people, more educated people, more well-off people, and married people. They also found that age has a different effect by SES, with lower SES groups beginning to show negative changes in health in their $30^{\prime} \mathrm{s}$ and peaking in their $50 \mathrm{\prime}$, while more affluent groups do not begin to have health changes until they are in their $70^{\prime} \mathrm{s}$. Kitagawa and Hauser (1973) found that lower SES groups had higher mortality rates whether income, education, or occupation was used as the indicator for SES.

Women have higher morbidity, but lower mortality than men at every age. Verbrugge (1989) addressed this question by controlling for acquired risks, psychosocial aspects, and health-reporting behavior. She found that women are more prone to acquired risks, largely stemming from their roles and stress, but they also have attitudes which encourage them to seek care 
and report illness in a different manner than men. When these factors are controlled, the trend is reversed and men have slightly higher morbidity as well as mortality.

In examining how SES affects health, Adler et al. (1994) noted that SES has a gradient effect on health, rather than a minimal level below which people are less healthy. This indicates it is probably not just a lack of some specific resource, but rather a combination of factors that contributes to health, and that all but the highest SES groups could benefit if policy makers and health care providers had a greater understanding this relationship.

Psychosocial variables and medical care

As the study by Adler et al. hinted, there is support that demographics and SES affect the intermediate factors of psychosocial variables and medical care. Four studies indicate how demographics may affect health behaviors. Dean (1989) found that women practice a greater number of health maintenance behaviors than men, which is expected because though women have higher morbidity rates, they have lower mortality rates in most age groups. Verbrugge (1989) pointed out that the higher morbidity rates for women are open to some reinterpretation as the trend reverses 
and men have higher morbidity if acquired risk, psychosocial aspects, and reporting behavior are controlled. A study of age (Rakowski, 1988) found that the relationship of variables affecting health and health practices was different for each of four different age cohorts. As bodies age, different concerns are likely to influence health decisions. Weaver, Parker, and Calhoun (1995) found that whites had significantly higher drug and alcohol use than did blacks or Hispanics. In addition, employment status and marital status was predictive of drug use, with single, working people using drugs more frequently. Education, income, and employment status were all predictive of alcohol use with more educated, wealthier, employed people using alcohol more frequently. And finally, Yeager, Macera, and Merritt (1993) found that sedentary behavior was related to race and lower income in women. Income and sedentary behavior have an inverse relationship and black women are more likely to be sedentary than white women even after controlling for income.

Several studies show the relationship of SES to stress. Adler et al. (1994) noted that stressful events are more frequently experienced by lower SES groups, and also that the perception of stress is 
greater for these groups, when controlling for frequency. Aldwin and Revenson (1986) noted a similar pattern related to mental health during a recession. Poorer people had greater exposure to economic stress, reacted more greatly, and recovered more slowly than their more well-off counterparts. McLeod and Kessler (1990) broke this question down further and found that while lower SES groups experience a greater number of stressful events, income is the significant component of SES in this prediction. However, income, education, and occupation all significantly influence the experience of distress with poorer, less educated, and less skilled workers suffering more distress for similar life events. These differential vulnerability studies support the indirect effect of SES on health in Williams' model.

Piechowski, in a review on the impact of multiple roles in women (1992) found that Karasek's "job strain model" could be used to explain women experiencing greater stress than men. In this model, high demands interact with low decision latitude to create distress. This combination of high demands and low decision latitude is much more common for women than men, both in the home, and in the work environment. In the same review, Piechowski noted that low income women were 
more likely to have the multiple roles of working, homemaking, and parenting and that this was more strongly related to distress in lower income women because they are less likely to be able to pay for assistance with home and child care responsibilities.

The relationship between psychosocial variables and health also has been extensively researched. Many studies are cross-sectional bringing up the question of causality, but Nowack (1991) did a longitudinal study and found that perceived stress, exercise, and avoidant coping were all significantly related to physical illness experienced a year later, after controlling for initial illness levels.

Wiebe and Williams (1992) in their review on hardiness noted that many of the illness models currently in use incorporate stress as a key component contributing to illness. Elliot (1995) reviewed articles relating stress to coronary heart disease. She noted that the relationship has been shown in men, but research on women has tended to assume the same relationship exists, rather than testing this empirically.

Berkman and Breslow, in a 1983 study found that for every age group, people with a greater number of high risk health behaviors had the highest mortality, while 
people with high numbers of low risk (health preventative) behaviors had the lowest mortality. Gottlieb and Green (1984) found that for women, social network (a concept related to but not synonymous with social support) and life events directly influenced health. However, age and education affected it only indirectly through these variables. For men, social network and education directly affected health while income and age affected it indirectly through social networks. In another study supporting the indirect effects of psychosocial variables on health, Dressler, Dos Santos, and Viteri (1986) found that psychosocial resources moderated the effect of race and poverty on blood pressure.

In their 1991 review on the effects of social support on health, Shumaker and Hill concluded that social support is reliably predictive of mortality, though this relationship is not as robust for women as it is for men. It also appears that in several studies there is a minimal level of social support required. People with lower levels have earlier mortality from many causes, however above this critical level the effect of incremental support diminishes or disappears. The relationship between SES and the factors affecting health is complicated. Belle (1990) found 
that while poverty increased stress, it also eroded social support, so the people with the greater stress also have fewer resources to cope with it. Dean (1989) found that socioeconomic circumstances had a greater influence on health behaviors than did attitudes or health knowledge. This finding is unfortunate because it indicates that simply educating the public will probably not have significant impact on health behaviors.

Briones, et al. (1990) found that among Mexican Americans, greater SES was related to greater social support and also greater institutional support (including medical care). Cockerham, Kunz, Leuschen, and Spaeth (1986-1) found that when matched by symptoms, poor people have greater physician utilization. Blacks and less educated people have more positive attitudes about doctors and believe a greater number of symptoms merit a medical visit. Cockerham and his colleagues believe that this shows that there is lower self-responsibility for health among lower SES groups. This translates to poorer health behaviors because these groups don't associate their own actions with their health. Another article notes that more affluent people still receive more preventative care than their less well-off counterparts (Cockerham, 
Leuschen, Kunz, \& Spaeth, 1986-2). Different components of SES seemed to influence different aspects of health and health care. Greater education reduced the number of symptoms reported, while greater income reduced the symptoms seen as meriting medical attention. Occupation had no impact. Of note is that behaviors in this study, when clustered as one variable, were unrelated to SES.

\section{Difficulties with Williams' Model}

The greatest problem with williams' model is one of utility. He argues that health is systematically tied to the social structure and that if we improve intermediate variables, new variables will arise to keep health and SES correlated as they currently are. Drastic changes in the social structure are not likely, and if we fully buy into Williams' arguments this would mean there is not a point in understanding or improving these relationships, because they will hold true even if it is with another factor taking the place of the psychosocial factor. However undoing the progress that has been made in sanitation and vaccinations because they have not caused the hoped for equilization in health does not seem called for either. It is hoped that Williams' model can be useful in pinpointing places where intervention can have the greatest impact 
on health, and that even if new factors do appear to mediate the relationship between SES and health, the strides made will have had an impact.

Another difficulty with Williams' model is the simplistic view of psychosocial variables. There are many studies showing that the psychosocial variables discussed have a more complicated relationship than clustering into a single variable. For example, Ensel and Lin (1991) found that social resources mediate the effects of social stressors on psychological wellbeing, and that psychological resources indirectly affect well-being by increasing social resources.

Health behaviors may be the most difficult variable to discuss. There is some evidence that behaviors are influenced by the other psychosocial variables, rather than clustering with them. In a study by Allison (1991) health behaviors were not directly influenced by social conditions, but rather were mediated by perceived behavioral control.

Behaviors are related to self-esteem, with greater esteem being associated with more positive behaviors (Muhlenkamp \& Sayles, 1986). Another study found that alcohol use and stress are highly related in men who use avoidant coping (Cooper, Russell, Skinner, Frone \& Muder, 1992). And finally, Umberson (1987) found that 
being married and a parent both had a deterrent affect on negative health behaviors, due to social control and family integration. In each case, health behaviors appear to be influenced by the other psychosocial resources.

The impact of psychosocial variables on health behaviors however, is difficult to pinpoint. Dean (1989) noted that social networks and lifestyle practices are related for women, but not men in a population older than 45. By clustering health behaviors with the other psychosocial variables, complexities such as this may be lost.

Behaviors do not reliably correlate with each other, so it is difficult to discuss them as one variable. Calnan (1989) found that behaviors were only modestly related to each other, and did not form a single dimensional variable. He noted that even in the presence of beliefs about specific health behaviors, a lack of perceived control may keep those healthy behaviors from occurring. Kronenfeld, et al. (1988) also found that health behaviors do not seem reliably associated with each other. They factor analyzed six health behaviors and found, not one, but three factors, which were different for men and women. 
Social support is equally complicated. Shumaker and Hill (1991) found that the relationship between social support and mortality appears different for men and women. Men appear to need a single reliable provider (usually a spouse) and this affects their health positively. Women on the other hand, have a more positive health impact if they have a greater number of providers and have greater frequency of contact with these other providers. Similarly, a review by Uchino, Cacioppo, and Kiecolt-Glaser (1996) concludes that different mechanisms of social support may be at work for men and women, but more research is needed to be sure.

Social support also seems to mediate the relationship between stressors and distress. In a 1992 review, Piechowski found that by providing tangible support with housework or childcare, husbands could reduce the distress felt by working mothers in relation to responsibilities and time constraints.

Franks, Campbell, and Shields (1992) point to family theory in discussing negative as well as positive effects on stress of social relationships. An example of negative social impact is from O'Brien, Wortman, Kessler, and Joseph (1993) in which homosexual men experienced greater distress as they reported 
increased social integration, because of the conflicting messages about sexuality during the early stages of the AIDS epidemic. They also found that increased peer validation was associated with higher levels of risk activity in that study. Fisher (1988) discussed AIDS preventative behaviors as they are influenced by selected reference groups. The group norms and values determine whether social support inhibits or supports AIDS preventative behaviors and when support inhibits the healthy behaviors, it also increases stress. It is likely that this is true in situations other than AIDS risk behaviors.

Yet while the above research hints at a very elusive relationship among variables, Zimmer-Gembeck and Helfand (1996) found psychosocial factors had a better fit for a low birthweight model when clustered together, than when examined separately.

\section{The Model and Pregnancy}

There is evidence in the research that the paths in Williams' model hold true in regard to pregnancy. For example, Poole and Carlton (1993) found that race, maternal age, income and education are all related to fetal mortality, supporting the paths from demographics and SES to health outcomes. Research shows that the age of the mother at conception is related to birth 
outcomes, with teens being much more likely to have preterm deliveries, still births, and neonatal deaths than post-adolescent mothers (Naeye, 1981). Low birthweight incidence reduces dramatically as women age through age 20, and at each age, black mothers have a $45 \%$ greater likelihood of delivering a low birthweight baby (Moore, 1988).

Cockerham, et al. (1986-2) noted that in general lower SES groups do not receive medical care until symptoms appear, supporting the path from SES to medical care. It is possible that this translates to later prenatal care among lower SES pregnant women. In fact lower SES groups are more likely to receive late or no prenatal care (Poole \& Carlton, 1993). These authors believe this is partly because they are less likely to perceive it as necessary. They also note that lower SES groups have greater barriers to medical care in terms of accessibility, ability to pay, and having a primary care giver. As would be expected, prenatal care is an important component of fetal health. Women who receive no prenatal care are three times more likely to deliver a low birthweight infant than mothers who receive early, continual prenatal care (Lia-Hoagberg, et al. 1990). This supports the path from medical care to health outcomes. Unfortunately, 
prenatal care level is affected by SES and race with poorer, less educated people, and minorities more likely to receive late or no care (Lia-Hoagberg, et al., 1990)

Behaviors and moods of the mother are also related to birth outcomes, supporting the path from psychosocial variables to health outcomes. ZimmerGembeck and Helfand (1996) found that smoking, low weight to height ratio or low weight gain (inadequate nutrition), negative mood, and rejection of pregnancy all were related to low birthweight.

A literature review by Tiedje, Kingry, and Stommel (1992) found support for both the behavioral and medical care variables affecting birthweight. The health behavior variables they found most often associated with low birthweight were inadequate prenatal care, poor nutrition, smoking, and moderate to heavy alcohol use.

other psychosocial factors also play a role in birth outcomes. Pagel, Smilkstein, Regin, and Montano (1990) found that life events stress accounted for significant variance in birthweight; and social support and anxiety were related to two Apgar measures after controlling for sociodemographics and biomedical risk. They also found that lower social support and high 
anxiety were associated with youth, low income, single marital status, lower education, smoking, and greater biomedical risk. Stress also appears related to maternal complications (Norbeck \& Tilden, 1983).

On the other hand, Lederman, in a review (1995) found mixed results in relation to stress and birth outcomes. Some studies reported relationships between stress and poor outcomes, some reported that the relationship was only indirect through substance use, and others reported no relationship. Social support as a buffer for stress also had mixed findings.

Fortunately, it appears that at least one potential intervention point might improve pregnancy outcomes. Collins, Dunkel-Schetter, Lobel, and Scrimshaw (1993) found that for a sample of low income women: 1) a greater quantity of social support was related to improved labor progress and Apgar scores, 2) better quality social support improved Apgar scores and decreased postpartum depression, and 3) larger social networks were related to higher birthweights. There was also some evidence of a buffering effect on stress, with greater support levels coinciding with lower stress levels. Zimmer-Gembeck and Helfand (1996) also found positive results of a support intervention. They found that women who received more than 45 minutes of 
psychosocial services had reduced rates of low birthweight regardless of risk profile. This relationship remained even after controlling for number of prenatal visits and time spent with nutrition or health education services.

Pregnancy outcome data is an appropriate place to test Williams' model, because of the huge benefits to understanding the components of a healthy pregnancy and birth. Infant complications, particularly low birthweight, can translate into chronic and handicapping conditions (Lia-Hoagberg et al., 1990). Improving birth outcomes will reduce the incidence of these conditions.

Poverty also is a more chronic problem for women, particularly single mothers and minority women (Belle, 1990). For women, this translates into poorer health, and this is not expected to improve on its own. Pappas et al. (1993) found that between 1960 and 1986 the disparity in health by SES increased $30 \%$ for black women and $23 \%$ for white women. For this reason, successfully defining ways to improve health for poorer people can do a proportionately greater amount of good. This is particularly true for pregnant women as positive change affects the health of two people. 


\section{Research Overview}

The current study tested Williams' model using data from a group of women who appeared for prenatal care in one of six clinics in the Portland, Oregon metropolitan area. The health outcomes examined were the maternal, labor, and infant outcomes of their pregnancies. Williams (1990) noted that infant mortality is often used internationally as a basis for comparing the health of overall populations. Given this, and the above support for his model in the general population, it was expected that Williams' model would hold true for the sample of mother/baby pairs.

For the purpose of testing William's model on pregnant women and their babies, a few minor changes were made so the model was more appropriate to the sample. Sex was not used as a demographic factor for this population because all subjects were women. Also marital status, which has been shown to influence health behaviors (Pill, Peters, \& Robling, 1993) was included with SES variables. Gottlieb and Green (1984) found that married people practice fewer detrimental health behaviors; they have lower alcohol intake and are less likely to smoke. Marital status also has been shown to affect health via social support (Sherbourne \& Hays, 1990). In pregnancy, marital status is of 
particular importance because of the stigma attached to unwed mothers (a stressor) and the greater perceived support of married people.

An argument could be made for including marital status within the social support variable. House (1981) argues that the minimum condition for experiencing social support is to have one or more stable relationships with others, and he believes the normative expectations revolving around marriage causes marital status by definition to be a social support variable. It was believed, however, that for the population in this study, marital status was more complex than this. Marital status is tied to household income, particularly for young, pregnant women. Education and occupation of a spouse or partner is also likely to have influence on the home environment. Marital status in this case influences social support, stress, and behaviors. In the case of pregnancy it is also a "status" variable. In addition, and most importantly, the SES variables in this study were objective and distinctive, while the psychosocial variables were subjective evaluations by the subjects, and so for initial modelling, marital status was included with SES. 
Age, while included in williams' model took on a different meaning in relation to pregnant women as the very young and very old do not bear children. The older and younger extremes in the child bearing years, however, are more prone to physical complications of pregnancy and delivery. Younger women are also more likely to be poor, unmarried, and less educated than women in their 20's or older (Weinman, 1990).

In Williams' model the psychosocial variable of perceived behavioral control is used as it has been shown to affect health (Calnan, 1989). In the data set used, control was not measured, however the variable of self-esteem was measured. Sheeran and McCarthy (1992) found private and public esteem both to be related to levels of depression, supporting that esteem is a psychosocial variable which affects health. Turner, Kessler, and House (1991) found that high self-esteem buffered the effects of unemployment (a form of stress) on four physical health outcomes. Self-esteem is a variable of particular importance in pregnant women because it has been shown to be related to prenatal care and infant outcomes (Norbeck \& Tilden, 1983).

Self-esteem and control seem to be separate concepts which often work in much the same way. Pearlin, Lieberman, Menaghan, and Mullen (1981) see 
mastery and self-esteem as the two components of self concept. Mastery refers to the extent to which people see themselves in control of the forces that importantly affect their lives. Philpot, Holliman, and Madonna (1995) found that locus of control was not a significant predictor of self-esteem. However, Cozzarelli (1993) examined perceived control and selfesteem and found a significant zero order correlation of .67 when both variables were used as components of self-efficacy.

The researchers who designed the primary study from which these data were taken added a perceived control question to the esteem measurement tool. They felt control was a component of self-esteem (Curry \& Wall, 1991). Perceived behavioral control is the variable Williams discusses, which is closer to perceived control than locus of control. Caution was used to note that self-esteem and control were not the same concept; however, due to the similarities and availability of the self-esteem data, self-esteem was substituted for perceived behavioral control to test williams' model.

In summary, the study utilized a secondary data analysis of pregnant women and their infants to test Williams' model. The goal was to test the model 
explaining the relationship between SES and health outcomes on this population, in hopes that intervention possibilities could be identified to improve pregnancy outcomes. The model tested is presented in Figure 2; and the relationship of the measurements to the factors is given in Table 1 .

\section{Research Hypotheses}

Preliminary work for the primary Curry and Wall study from which the data for this study were taken indicated that biomedical and sociodemographic risk factors could only explain about $40 \%$ of the variance in infant birthweight with a hoped-for improvement of $10 \%$ (to 44\%) when considering psychosocial variables.

The hypotheses for this study were as follows:

1) Williams' model fits the data; however the path from biomedical factors to psychosocial factors is not significant.

Typically in Portland, Oregon, we may not expect demographic paths to SES and psychosocial variables to be significant because the population has a small proportion of ethnic minority women. This leads to a smaller amount of variance in the demographic variable causing it to lose some of its predicative ability. 
Figure 2: Proposed Model

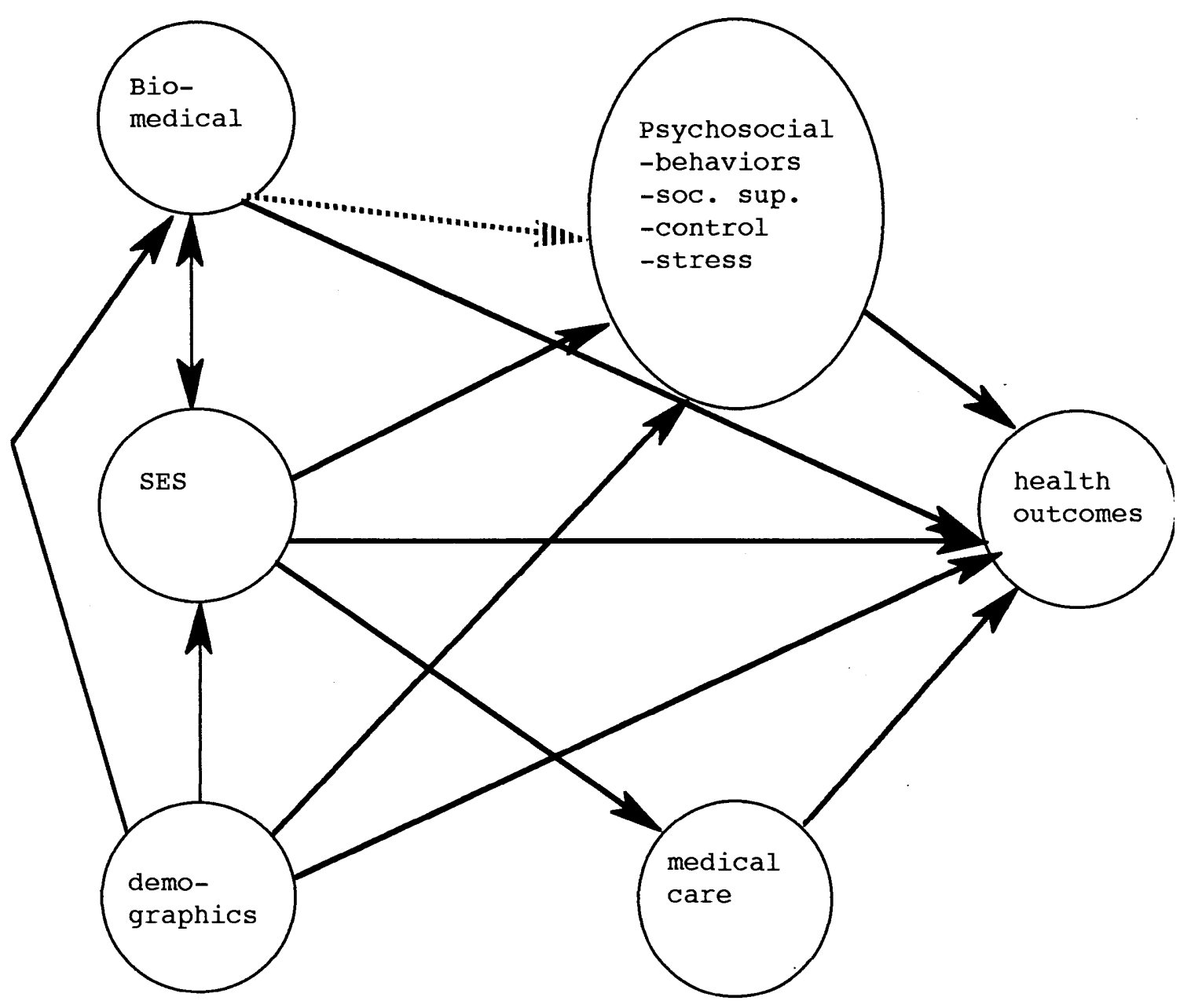

*dotted line indicate path expected to be insignificant 
Table 1

Measurement Model and the Latent Factors they Indicate

\section{Initial Variables}

\begin{tabular}{|c|c|c|}
\hline Demographics & Socioeconomic status & Biomedical \\
\hline Age & Income & Biomedical \\
\hline Race & $\begin{array}{l}\text { Education } \\
\text { Occupation }\end{array}$ & $\begin{array}{l}\text { risk } \\
\text { assessment }\end{array}$ \\
\hline
\end{tabular}

\section{Intermedicate Variables}

Psychosocial

Support Behaviors Inventory (Social Support)

Rosenberg's Self-Esteem Scale

Stress Measure

Behaviors

(smoking, marijuana, alcohol \& drug use; beginning weight; weight gain)

Medical Care

Week of lst prenatal visit

Number of prenatal visits

2nd trimester risk assessment

Final ariable

Health Outcomes

Birthweight

Weeks gestation

Five minute Apgar score

Infant complications

Delivery complications 
The researchers, however, oversampled African-American women, and several of the clinics were in areas with higher ethnic populations, therefore these paths were expected to be significant. The sample was also predominantly poor, and so due to the lack of higher SES subjects, it was believed the role of SES might be decreased as a predictor; the paths leading from SES however, were still predicted to be significant. Research indicates that the inital biomedical risk and medical care have a strong effect on health outcomes, so these paths were expected to be significant. Biomedical risk was also expected to influence the psychosocial factor. While it was believed this is probably true of the general population, it was expected there would be low numbers of people with extremely high biomedical risk, so this relationship would not be significant. Of particular interest was the path from psychosocial variables to health outcomes, as this could indicate potential for interventions. It was expected this would be significant. 
2) Time 2 psychosocial variables account for a significant amount of variance in birth outcomes after controlling for time 1 psychosocial variables.

It was expected that the healthiest birth outcomes would be among women who have high social support, low stress, high self-esteem, and healthy behaviors all the way through their pregnancy. However, since not all women are in this ideal circumstance, it was expected that positive changes at any point, particularly for those who started with poor scores, would have a positive impact on outcomes. Controlling for time 1 psychosocial variables allowed initial levels of psychosocial variables to be of primary importance, while hierarchically adding the time 2 variables tested to see if changes really had the expected positive impact.

\section{Method}

Data were collected as part of a research project testing a biopsychosocial model to predict low birthweight (LBW) and poor delivery outcomes. The primary researchers on this project were Mary Ann Curry and Eric Wall of Oregon Health Sciences University. 
The data were used for the current project with their permission.

Data were requested with all identifying variables removed since they were not required for this study's research goals. Because the data was an existing set, and no identifying variables were received, a Human Subjects Research Review waiver was filed.

\section{Subjects}

Subjects were women who entered the Oregon Health Sciences University clinic, or one of five other county clinics in Multnomah or Clackamas counties in Oregon, for an initial prenatal visit during the period beginning in 1992 and ending in 1995. There were 1937 women in the first data collection, however a large number either did not have a prenatal visit between 24 and 28 weeks or had their first prenatal visit after the 20 th week and so do not have the second wave of data. In all 753 women had a complete data set for time 1 and time 2. All women who participated and subsequently delivered babies in oregon have outcome, or time 3 , data available $(\mathrm{N}=1630)$.

To qualify, subjects needed to speak English and be carrying a single pregnancy. African-American women were oversampled because of the low proportion of minorities in the Portland population and because of 
the importance of expected racial differences to birth outcomes. In addition to the oversampling, many of the clinics also serve culturally diverse groups. Thirtysix percent of the sample was expected to be of ethnicminority backgrounds. In the final sample, 63.48 were Non-Hispanic Caucasians, so $36.6 \%$ were of ethnicminority backgrounds.

\section{Data Collection}

All interview data were collected by trained research assistants (RA's). Data were collected in three waves (for most subjects). There was no manipulation of the timing of the first prenatal visit, as the timing of first contact with prenatal care was believed to be a risk variable in the study. At the first prenatal visit, subjects were approached in the examining room. If they agreed to participate, sociodemographic data, stress, social support, self-esteem, lifestyle and habits, and biomedical risk were measured. The biomedical information was taken from hospital charts, the lifestyle and habits portion was a confidential written survey, and all other data were collected through an interview. The second data collection occurred between the 24 th and 28 th week of gestation. If the first visit occurred after the 20th week gestation, all data for time 1 and 2 (with no 
duplication) were collected at once. The time 2 data set included stress, social support, self-esteem, lifestyle and habits, and a second trimester biomedical risk assessment. Again, the biomedical information was taken from medical charts. Because this information was taken from medical charts, it was available for all women who remained in Oregon, even if they did not have a second trimester prenatal visit. In both of the interviews, the Iifestyle and habits component, which was made up of substance use items, was filled out privately by the subjects and put in a sealed envelope until after delivery to ensure confidentiality to subjects and relieve the researchers of ethical dilemmas. After delivery, total number of prenatal visits was summed, and outcome measures were taken from hospital charts and birth certificates. All data collection forms are attached as Appendix A.

\section{Specific Tools as Used in the Current Study}

The current study used these data to test a model proposed by David Williams (see Figure 2) to explain the relationship between SES and health outcomes. The variables in the data set were used to indicate the model variables as follows: 


\section{Initial Latent Variables:}

Demographics: The variables age and race were used to indicate demographics. Because of the small number of minorities other than African Americans, other minorities were grouped together. This variable was dummy coded, with a variable to indicate African American race and a variable to indicate Caucasian/Asian race. The Caucasian/Asian variable included Asian race with Caucasians as Asians more closely resemble Caucasians than they do other minorities in terms of education, occupation, and age. According to the model, demographics influence SES, biomedical factors, psychosocial factors, and health outcomes. Its variables are not affected by the other factors.

\section{SES Latent Variable: Socio-economic status was} conceptualized as a result of marital status, education, income, and occupational variables. Income was self-reported monthly family income. Education was number of years of formal education with a GED also equalling 12 years of education. Occupation was a measure of working or not, and whether work involved physical labor or not. Each of these questions was related to a dummy variable and together they indicated the occupation variable. Marital status was married 
living with partner; married, living alone; single living with partner; and single living alone. Two dummy variables were used to indicate marital status: married versus not married and living with a partner versus not living with a partner. SES is influenced by demographics and correlated with biomedical factors. It was believed to influence medical care, psychosocial variables, and health outcomes.

Biomedical Latent Variable: This was evaluated through the Biomedical Risk Assessment, made up of items from the risk assessment tool for OHSU and additional non-duplicative items for the Bowman Gray School of Medicine assessment tool. The primary researchers who collected this data believed the combination would have more predictive capability than either instrument alone (Curry \& Wall, 1991).

The OHSU risk assessment tool was based on scales developed from Hobel and colleagues (Hobel, Hyvarinen, \& Okada, 1973; Hobel, Youkeles, \& Forsythe, 1979) and Goodwin, Dunne, and Thomas (1969). Wall, Sinclair, Nelson, and Toffler (1989) found a positive predictive correlation of .07 between this instrument and low birthweight when the instrument was used at the time of the first prenatal visit. The correlation improved to .20 when the instrument was used at week 37 . The 
correlation between initial assessment and week 37 assessment was .43 .

The Bowman Gray School of Medicine Instrument included empirically derived factors from the medical literature and tested on a population of 11,623 women (Ernest, Michielutte, Meis, Moore, \& Sharp, 1988). The initial risk assessment has a higher level of predictive validity than other reported instruments depending on where the cut-point for high risk is assigned. When high risk was defined as the top $10 \%$ of scores the positive predictive value $(\mathrm{PPV})(+)$ was .26 and $\operatorname{PPV}(-)$ was .92 . When high risk was expanded to the top $30 \%$ of scores PPV(+) increased to .42 while PPV(-) declined to .78 . Items from the OHSU and Bowman Gray School of medicine tools which were more appropriate to assess SES, demographics, or psychosocial factors were moved to those assessment tools.

The biomedical risk assessment was a list of 43 items indicating risk. Yes or no was indicated for each item and a cumulative risk score was assigned, so theoretically there was a maximum score of 43 . This information was taken from medical charts.

The total score on the biomedical risk assessment was seen to be appropriate for the biomedical factor in Williams' model because the tool included the 
biomedical factors relevant to a healthy pregnancy and delivery. This information was taken from patient medical charts. Biomedical factors were expected to influence the psychosocial factor and health outcomes.

\section{The Intermediate Variables are:}

Medical Care Latent Variable: The medical care variable was indicated through total number of prenatal visits, the weeks gestation of the initial prenatal visit, and the second trimester risk assessment. The second trimester risk assessment included factors that had developed or been discovered since the onset of pregnancy such as anemia or complications in carrying the fetus. These risk items were developed from the literature and the Bowman Gray School of Medicine Risk Index (Ernest et al., 1988). This instrument had 36 items and each item was answered yes or no according to risks that had been discovered or had developed during the pregnancy. All of this information was taken from medical charts and was pregnancy related. Medical care was expected be influenced by SES and to influence health outcomes.

Psychosocial Latent Variable: Psychosocial data for stress, social support, self-esteem, and lifestyle and habits were collected at both the first and second interview. For the purpose of testing the model, the 
time one data were used. One of the goals of the current research was to identify places in the course of prenatal care where intervention might be most effective in influencing favorable outcomes. It was assumed that the earlier a positive change in psychosocial variables occurred, the greater the impact would be (Curry \& Wall, 1991).

The Prenatal Psychosocial Profile (PPP) was used to measure stress, social support, and self-esteem. This consisted of three measures; Brown's Support Behaviors Inventory (SBI) (Brown, 1986) was used to evaluate two measures of social support. Each had 11 items of support and subjects responded for both their partner and other people on how satisfaction with that component of support. The satisfaction scales ranged from 1 (very dissatisfied) to 6 (very satisfied). Subjects with no partner were given the median score on the partner item, as it was believed absense of a partner neither indicated satisfaction nor dissatisfaction in terms of support. There are three potential scores from the SBI: partner, other, and a combined score. Brown reported face validity and internal consistency reliabilities of .90 or greater for the three measures when the SBI was administered to a sample of pregnant women. 
Self-esteem was evaluated with 10 items from Rosenberg's Self-Esteem Scale (Rosenberg, 1979) and an 11 th item about perceived control which was added by Curry and wall for these data because they felt control was an important component of self-esteem (Curry \& Wall, 1991). The self-esteem subscale was made up of 11 statements about self-feelings. The subject was to select from four agreement options; strongly agree (1) to strongly disagree (4). The Rosenberg Self-Esteem Scale had internal consistency coefficients of between .84 and .87 on pregnant samples.

The stress measure was compiled by Curry from other instruments. This stress measure included 11 Likert type items, 10 of which were from Lazarus and Folkman's Hassles and Uplifts Scale (Kanner, Coyne, Schaefer, \& Lazarus, 1981) and Sarason's Life Experience Survey (Sarason, Johnson, \& Siegel, 1978) . The stress subsection had 11 life variables and subjects were to indicate on a four point scale whether these caused no stress $(=1)$ to severe stress $(=4)$.

The full Prenatal Psychosocial Profile instrument was pretested on two samples of pregnant women and findings supported the validity and reliability of the instrument. The stress measure was significantly correlated with the Difficult Life Circumstances Scale 
$(r=.71)$ indicating convergent validity and the testretest correlations ranged from .78 to .84 for the three PPP subscales. Stress was found to correlate negatively with social support and self-esteem as expected, and social support and self-esteem were positively correlated.

Lifestyle behaviors were also a part of the psychosocial factor in Williams' model. These were evaluated here through a survey evaluating frequency of smoking, marijuana use, alcohol use, and hard drug use. All of these items were self-reported. The tool used for this was a variation of Norbeck and Anderson's (1989) Your Lifestyle and Habits Questionnaire. This was administered to subjects who completed the questionnaire in private and sealed it in an envelope. Researchers did not open these until after participants delivered their babies. Nutritional and sexual practice variables were not included on this tool because of the difficulty in measurement and a belief that information would not be given freely and accurately. Variables indicating nutritional and sexual practice variables, however, were included in the risk assessment inventories (i.e. development of STDs or inappropriate weight gain). The current model conceptualized weight maintenance as a health behavior 
so beginning weight and weight gain were included in the psychosocial factors latent variable, rather than in the risk assessment variables. Both variables were dummy coded variables with mother's beginning weight between 100 and 200 pounds (healthy) versus not, and with weight gain of less than 8 pounds (risky) by the 24 th to 28 th week versus more than 8 pounds.

\section{Health Outcome Measures:}

One goal of the current research was to identify variables that optimize positive outcomes as well as minimize negative ones. Health outcomes were indicated by birthweight, weeks gestation, 5 min. Apgar score1, infant complications (sum of presence of growth retardation, Meconium staining 2 , and transfer to neonatal intensive care) and delivery complications (a sum of presence of induced labor, use of vacuum or forceps, Cesarean delivery, longer than normal delivery (1st and 2nd stage), epidural analgesia, narcotic analgesia, high blood pressure, and early rupture of membranes.) This information was taken from hospital charts and birth certificates.

1. Apgar score is a rapid and semi-quantitative assessment of the infant based on five signs indicative of the physiological state of the neonate. Heart rate, respiration, muscle tone, reflex ability and color are each scored 0,1 , or 2 , with 2 being healthiest, for a maximum of 10 points. Apgar scores are correlated with morbidity and mortality. (Bobak \& Jensen, 1991)

2. Meconium staining of the amniotic fluid indicates passage of meconium from the fetal bowel before birth. This may indicate fetal distress. 
Pregnancy Outcomes

\section{Results}

For the purpose of analysis, multivariate, normal distributions were assumed; it was also assumed that errors were randomly distributed.

\section{Descriptive Data}

Sociodemographic information:

Subjects were 1937 women between the ages of 13 and $44(x=23.67 ; s d=5.95)$. All women completed the first interview. Sociodemographic information for the sample is summarized in Table 2. Seven-hundred and fiftythree women completed the second interview and 1630 had birth-chart data available for the final time point in data collection. The medical information for time 2 was available through medical records and any nonduplicated time 2 items were collected at the first interview if it occurred after the twentieth week. In all, there were 1144 women with no missing information for the purpose of the covariance structure model and 753 with all time 1 and time 2 information for the regressions.

Racially the sample was $63.1 \%$ Caucasian, $21.0 \%$ African-American, 3.1\% Native American, 4.1\% Hispanic, $2.8 \%$ Asian and $5.5 \%$ other. The numbers of minorities other than African Americans were not large enough to be included as individual variables in the covariance 
Pregnancy Outcomes

Table 2

Sociodemographic Descriptive Information

\begin{tabular}{lccc} 
& Range & Mean & sd \\
\cline { 2 - 2 } & $13-44$ & 23.7 & 6.0 \\
Education & $6-23$ & 12.1 & 2.1 \\
Income & $0-9999$ & 1123 & 1218
\end{tabular}

Caucasian

Percent

African American

63.1

21.0

3.1

4.1

Hispanic

Asian

2.8

Other

5.5

Married

$\frac{\text { Live W/Partner }}{27.7}$

Not Live $\mathrm{W} /$

Not Married

26.8

2.8

41.5

Working

Physical Job

39.4

9.4

$\mathrm{n}=1937$ for sociodemographic information 
structure model and so dummy variables for

Caucasian/Asian and African American were used with other minorities clustered together for the baseline information. Asians were clustered with the Caucasians due to the fact that they were most similar to Caucasians on income, education, and age.

Percentages of women who were married, living with their partner; married, living alone; single, living with their partner; and single, living alone were 28.7, $2.8,26.8$ and $41.5 \%$ respectively. Average education was 12.07 years; the range was 6 years to 23 years with $s d=2.13$ years. Average monthly income was $\$ 1,123.31$ with $s d=\$ 1,217.96$. Women with jobs outside the home made up $39.4 \%$ of the sample and women with jobs involving heavy physical labor made up $9.4 \%$.

\section{Biomedical Descriptives:}

The initial biomedical risk assessment had 43 risk items which were to be answered 1 for the presence and 0 for the absence, for a potential score of 43. Among participants in this study the range was 0 to 21 . The mean score on the biomedical risk variables was 2.77 . The second trimester risk assessment had a similar format but consisted of 36 items of risks which had developed during the current pregnancy. The range of scores in this sample was 0 to 8 out of the possible 
36, with a mean of .85. This means on average women began their pregnancy with 2.77 risk factors and over the first two trimesters developed another .85. Women on average began their prenatal care at 12.77 weeks gestation. The range was from week 1 to week 41 with a standard deviation of 6.5 weeks. When the sum of total prenatal visits was examined a complication was discovered. The range of prenatal visits was 1 visit to 32 visits with a median of 10 visits and $70 \%$ of the sample having $8-15$ visits. Visits higher than the $8-15$ range most likely indicated higher risk pregnancies and not superior care. Since this variable did not have a linear relationship with quality of medical care, it was recoded; below 8 visits was recoded to 0 , signifying inadequate care, and 8 visits and above was coded as 1 signalling adequate care.

\section{Psychosocial descriptive information:}

The Prenatal Psychosocial Profile was made up of 4 sub-scales, each with 11 questions. The stress and esteem sub-scale items had a 4-point range for each question giving the sub-scales a range from 11 to 44 . Actual scores in this population ranged from $11-44$ for esteem, and 11 - 36 for stress. The support subscales had questions with a 6-point range and so had a range of 11 - 66. Both the support from partner and 
support from others sub-scales had people with minimum and maximum range scores.

Mean scores on the sub-scales were $19.46,51.33$, 52.01 , and 35.37 for the stress, partner support, other support and esteem components respectively. Standard deviations were $4.94,12.30,11.36$, and 5.58 .

The percentages of women who reported using no substances at all at the initial prenatal visit were $64.8 \%, 92.9 \%, 92.9 \%$ and $98.5 \%$ for smoking, marijuana, alcohol, and drugs respectively. The percentage of women falling in the healthy starting weight range (between 100 and 200 pounds) was 83.7\%, and the percentage of women who had gained at least 8 pounds by the end of the second trimester was $90.7 \%$.

Relationship of Psychosocial Variables:

Eight of the ten psychosocial variables were measured at two points in time. As would be expected, time 1 and time 2 psychosocial variables were all significantly correlated. Table 3 shows the correlations of each of the 8 psychosocial measures at time 1 with the same measure at time 2 .

Table 4 shows the correlations of the eight psychosocial measures with each other at time 1 . Smoking was significantly related to using marijuana and alcohol; and alcohol and hard drug use were 
Pregnancy Outcomes

53

Table 3:

Correlations of the Psychosocial Variables

Time 1 and Time 2

$\underline{\text { Str2 }} \underline{\underline{P a r t 2}} \underline{\text { ot2 }} \underline{\underline{E} t 2} \underline{\text { Smk2 }} \underline{\text { Min2 }} \underline{\text { Alc2 }} \underline{\text { Drg2 }}$

Stress $1 \quad .59$

Partnerl $\quad .64$

Otherl $\quad .56$

Esteem 1 $\quad .74$

Smokingl $\quad .82$

$\operatorname{Marij.1}$

.53

Alcoholl

.41

Drugs 1

*All correlations are significant ( $<<.001)$

$\mathrm{n}=753$ for correlations between time 1 and time 2 . 
Pregnancy Outcomes

\section{Table 4 \\ Inter-correlations of the Psychosocial Variables}

Stre Part oth Est Smk Marij Alc Drg

Stress 11.00

Partner $1-.38 * 1.00$

Other1 $-.31 * .17 * 1.00$

Esteem $1 \quad-.45 * \quad .32 * \quad .24 * 1.00$

Smoking $1.12 *-.10 *-.09 *-.10 * 1.00$

Marij.1 .09* $-.09 *-.01-.03 \quad .11 * 1.00$

Alcoholl $.08 * \quad-.02-.05 \quad-.05 \quad .12 * \quad .11 * 1.00$

Drugs $1 \quad .08 * \quad-.04-.02-.04 \quad .09 * \quad .18 * .16 * 1.00$

* indicates significance $(p<.01)$

$\mathrm{n}=1630$ for correlations involving substance measures;

1933 for those not involving these measures. 
correlated. The Prenatal Psychosocial Profile items were all significantly inter-correlated as expected at both time 1 and time 2 . The partner support and other support measures and self-esteem were all positively correlated. Stress negatively correlated with all three.

\section{Outcomes Descriptives:}

Descriptive informationabout the outcomes measures can be seen in Table 5. Average birthweight was 3356.46 grams. The range was 350 - 6265 grams with a standard deviation of 609 grams. Average gestational age was 39.01 weeks. The range was 19 weeks to 43 weeks and the standard deviation was 2.24 weeks. Average 5-minute Apgar score was 8.75 with a low of 0 and a high of 10. Standard deviation was .95. There was an average of .59 infant complications, with a range of 0 to 3 and a standard deviation of .83 .

\section{Confirmatory Factor Analysis}

The measurement model for the confirmatory factor analysis can be seen in Table 6 and was as follows:

Demographics: Demographics was indicated by age and race. Race was comprised of two dummy coded variables for African American race and Caucasian/Asian race. 


\section{Pregnancy Outcomes}

Table 5

\section{Outcomes Statistics}

$\begin{array}{lrrr} & \text { Range } & \text { Mean } & \text { sd } \\ \text { Birthweight } & 350-6265 & 3356.46 & 609 \\ 5 \text { minute Apgar } & 0-10 & 8.75 & .95 \\ \text { Gestational age } & 19-43 & 39.01 & 2.24 \\ \text { Delivery Comps. } & 0-3 & .59 & .83 \\ & & & \\ n=1629 \text { for outcomes data } & \end{array}$




\section{Table 6: Measurement Model}

\section{Confirmatory Factor Analysis}

Initial Variables

$\begin{array}{ll}\text { Demographics } & \frac{\text { Socioeconomic Status }}{\text { age }} \\ \text { race } & \text { education } \\ & \text { occupation } \\ & \text { marital status }\end{array}$

Biomedical biomedical risk assessment

Intermedicate variables

Psychosocial

Support Behaviors Inventory (Social Support)

Rosenberg's Self-Esteem Scale

Stress Measure

Behaviors (smoking, marijuana, alcohol \& drug use; beginning weight; weight gain)

Medical Care

Week of lst prenatal visit

Number of prenatal visits

2nd trimester risk assessment

Final variable

Health Outcomes

birthweight

weeks gestation

five minute Apgar score

infant complications

delivery complications 
SES: SES was indicated by income, education, occupation, and marital status. It was recognized that marital status may not load on the SES variable. Marital status is considered a form of social support, and while in this population it was believed to be tied to the larger concept of socioeconomic status, if it did not load here it would have been moved to the psychosocial factor as a part of social support.

Biomedical factors: The biomedical factor was indicated by the total score on the biomedical risk assessment tool.

Medical care: Medical care was indicated by the number of weeks gestation where first prenatal care was received, the number of total prenatal visits prior to delivery, and the total score on the second trimester biomedical risk assessment.

Psychosocial factor: The psychosocial factor was indicated by the Prenatal Psychosocial Profile, which had three sub-sections for stress, social support, and self-esteem, and by the lifestyle and habits survey.

The lifestyle and habits survey was made up of quantity options for four different substances; cigarettes, marijuana, alcohol, and hard drugs. The beginning weight from the initial biomedical risk 
assessment and weight gain from the second trimester risk assessment were also behavior measures on the psychosocial factor. Beginning weight was coded so that 100-200 pounds $=0$ and over or under that range $=$ 1. The weight gain from the second trimester risk assessment was coded so that gaining at least 8 pounds $=0$ and gaining less than 8 pounds $=1$. All of these variables except the weight measures were measured at time 1 (initial prenatal visit).

It was recognized that this latent variable was complex and that there was a possibility that not all the factors would load on this variable. The lifestyle and behavior assessment was the variable most likely to not load, as the research had shown behaviors to be a complicated phenomenon. If this measurement did not load on the psychosocial latent variable, it would be dropped for the purpose of testing Williams' model.

Health outcomes: Health outcomes were indicated by birthweight in grams, weeks gestation, five minute Apgar score, infant complications (sum of presence of growth retardation, Meconium staining, and transfer to neonatal intensive care), and delivery complications (a sum of presence of induced labor, use of vacuum or forceps, Cesarean delivery, longer than normal 1st and/or second stage of labor, epidural analgesia, 
Pregnancy Outcomes

narcotic analgesia, high blood pressure, and early rupture of membranes).

The sample was sufficient to test the model given that there were 28 variables, including the dummy variables, used to indicate the model.

A confirmatory factor analysis was run as specified by the measurement model (Table 6) using LISREL. Chisquare was 3155.38 with 336 degrees of freedom for a ratio of 9.39. The adjusted goodness of fit was .871 and the root mean square residual was .066 . These indicators all indicated adequate fit for the model.

In confirmatory factor analysis and covariance structure modelling, t-values are given to show the significance of various individual relationships within the model. T-values of greater than 2 indicate significance. Two single measures and one pair of measures did not significantly load on the specified factors, meaning the relationship between the measurement items and the factors they were meant to indicate were not strong. The sum of prenatal visits did not load significantly $(\underline{t}=-.397$ ) on the medical care factor. There were two other variables left to indicate the medical care factor so this variable was dropped. The summary variable of presence or absence of delivery complications had a factor loading of .001 
and a t-value of -.412 on the outcome factor. There were four other variables to indicate the outcome factor so this variable was dropped.

Finally, the two measures of weight; initial weight and weight gain did not load significantly on the psychosocial variable. Initial weight had a t-value of 1.609 and the weight gain variable had a t-value of .026. Both variables were dropped from the psychosocial factor. Since the original researchers believed these variables were medical risk variables, and for the current study these measures had been extracted from the biomedical risk assessments and moved to the psychosocial factor; these items were returned to their original measurement tools. Initial weight was returned to the biomedical risk assessment and weight gain was returned to the second trimester risk assessment.

A new confirmatory factor analysis was run with the above mentioned changes. All measures significantly loaded on their specified factors. The adjusted goodness of fit was .872 and the root mean square residual was .067 . Chi square $=2649.59$ with 238 degrees of freedom, or a ratio of $11.13(\mathrm{p}<.001)$. All t-values were significant. The highest modification index was 413.5 ; the second highest was 
201.1. Only two other indices were above 50. None of these variables was freed to load on the other factors as it was believed that the structural model which allowed for relationships between the factors would address these high indices. Factor loadings for the latent variables can be found in Table 7 .

The Covariance Structure Model Test for Williams' Model The covariance structure model was run using LISREL and pairwise deletion of missing cases was specified. The structural model, or the relationship of the latent factors to each other, can be seen in Figure 3. The measurement model, which is the relationship of the individual measurement tools to the factors can be found in Table 8. Chi square was 2686.96 with 241 degrees of freedom. This was a ratio of 11.15 ( $p<$ $.001)$. The adjusted goodness of fit was .871 and the root mean square residual was .068 . In evaluating the fit of a covariance structure model, an adjusted goodness of fit greater than .8 and a root mean square residual less than .08 indicate adequate fit. All of these indicators were in line for this model.

The range for standardized residuals was -21.3 to 21.9. Scores were normally distributed with $21.4 \%$ of the residual scores outside the $+/-3$ standard deviation range. 
Table 7

Factor Loadings for the Measurement Variables

\section{$\underline{\text { SES }}$}

Income

Education

.686

Married

Living with Partner

.636

.599

.564

Working

Physical Job

Biomedical Risk

Biomed. Risk

1.000

Medical Care

Weeks Gestation

(1st Prenatal Visit)

2nd Trimester Risk

Psychosocial

\begin{tabular}{lr}
\hline Stress & .711 \\
Partner Support & -.530 \\
Other Support & -.365 \\
Esteem & -.616 \\
Smoking & .229 \\
Marijuana & .131 \\
Alcohol & .099 \\
Drugs & .111
\end{tabular}

Outcomes

Birthweight $\quad .718$

5 Minute Apgar .355

Gestational Age $\quad .908$

Infant Complications $\quad-.212$

Demographics

Age

African American $\quad-.839$

Caucasian/Asian $\quad .855$

$\mathrm{n}=1134$ 


\section{Pregnancy Outcomes}

Figure 3: Model with Path Coefficients and t-Values

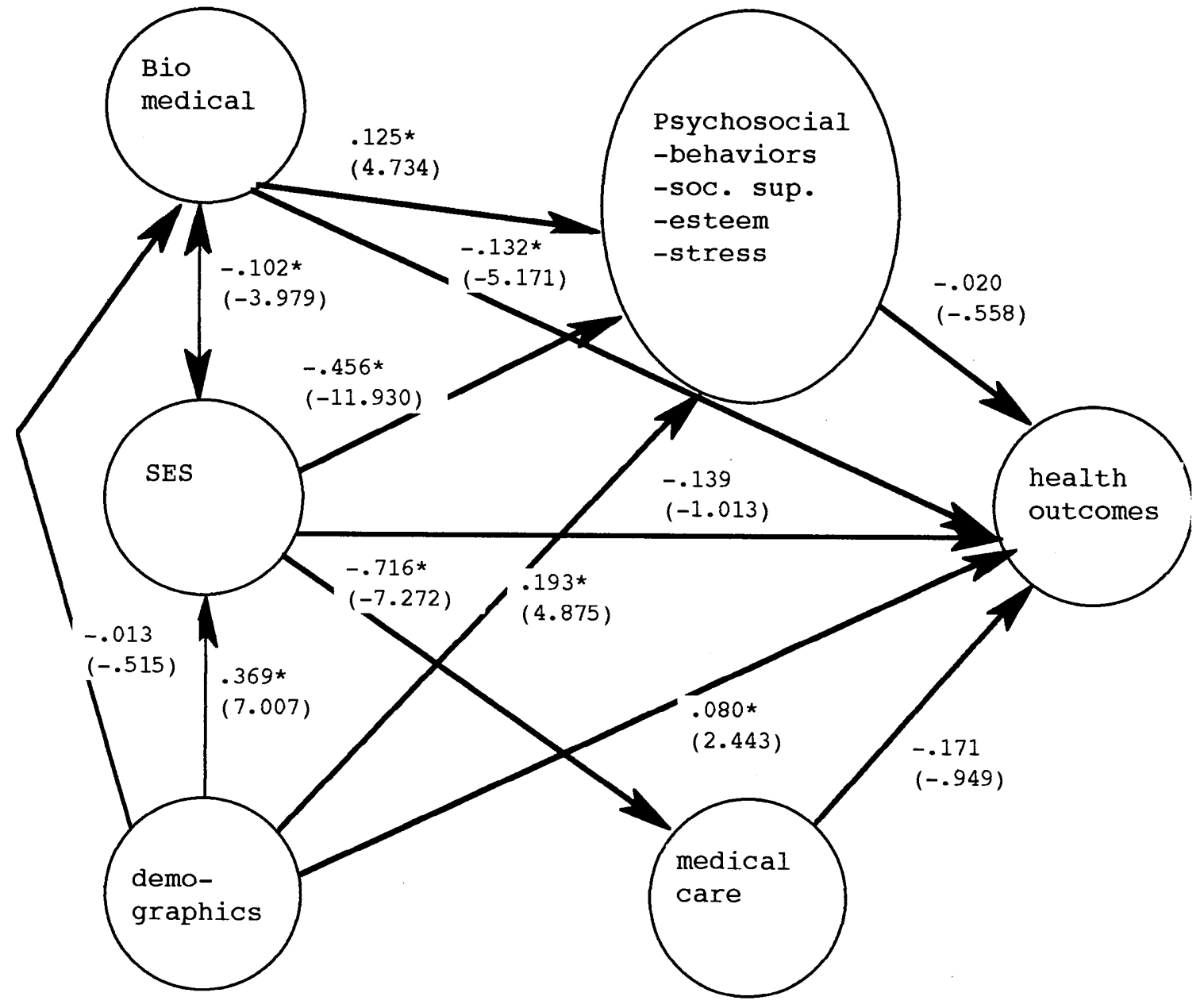

* indicates significant paths t-Values are in parentheses $\mathrm{n}=1134$ 
Pregnancy Outcomes

Table 8

Lambda Loadings for the Measurement Model

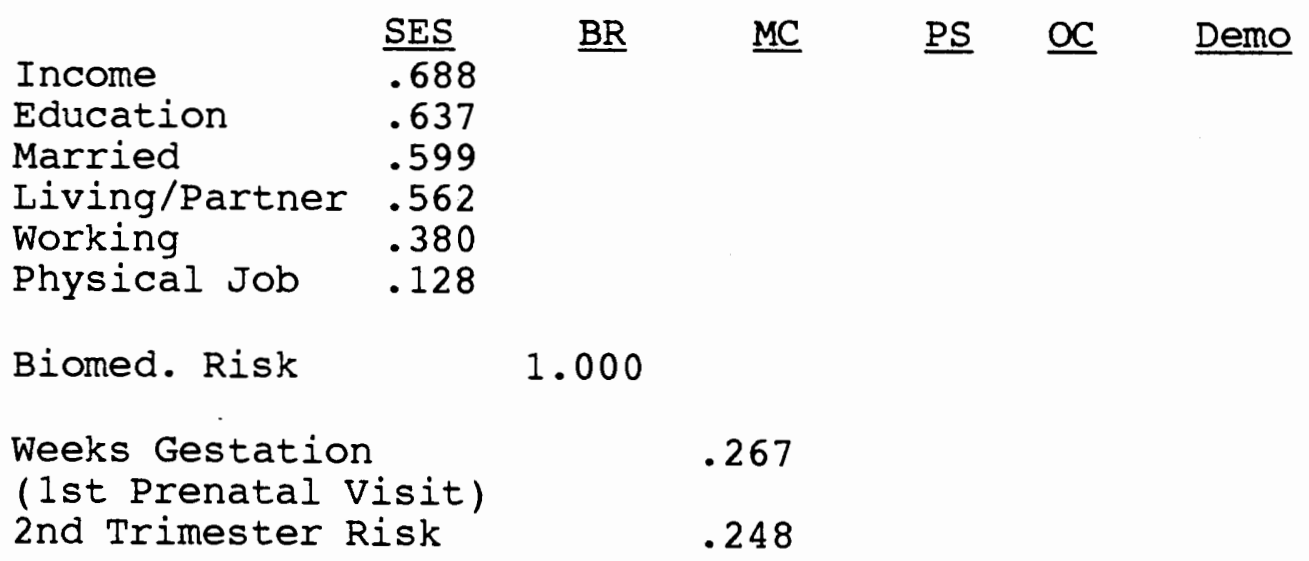

\section{Stress}

Partner Support

Other Support

Esteem

.709

Smoking

$-.531$

$-.365$

$-.617$

Marijuana

Alcohol

.231

.131

Drugs

.100

.112

Birthweight

5 Minute Apgar

Gestational Age

Infant Complications

$-.212$

Age

African American

Caucasian/Asian

$\mathrm{n}=1134$ 
The measurement model with factor loadings is presented in Table 8 . All t-values in the measurement model were significant as expected from the confirmatory factor analysis.

The highest modification index was 60.95 . In addition, there was one score in the $50^{\prime} \mathrm{s}$ and 4 scores in the 40 's. If each modification index were freed to load on the factor specified it would decrease the Chi square value by the amount of the index and decrease degrees of freedom by 1 . With a Chi square of 2686.95, this range of change would not have had a substantial impact on the overall fit. Also none of these relationships could be supported theoretically, so they were not included in the model.

The path coefficients (betas) and t-values for the paths of the model can be seen in Figure 3. The path coeficients are similar to regression coefficients, except that instead of indicating the strength of the relationship of individual measures, they indicate the strength of the relationship of the latent factors. Seven out of eleven of the structural paths were significant. Unfortunately, three of the nonsignificant paths were direct paths to the outcomes measures. The insignificant paths were from 
demographics to biomedical risk, SES to outcomes, psychosocial variables to outcomes, and medical care to outcomes.

The outcomes factor only had a squared multiple correlation of .038 , meaning the variance explained in the health outcomes factor by the other variables in the model is $3.8 \%$. The variance explained in the medical care variable and the psychosocial risk variable are $51.3 \%$ and $20.7 \%$, respectively. Both of these numbers are substantial. Fifty-one percent of the variance in medical care can be explained by SES alone, indicating a powerful relationship; and $20.7 \%$ of the variance in psychosocial risk can be explained by demographics, SES, and biomedical risk, as indicated by the paths in Figure 3 .

\section{An Alternative Model}

While the data fit Williams' model, because of the nonsignificant paths to outcomes and the low variance in outcomes explained, an alternative model was examined. A new covariance structure model was run with the four substance use items separated from the psychosocial latent variable. This model can be seen in Figure 4. In this model, behavior (substance use) mediates the relationship between the psychosocial latent variable and outcomes. 


\section{Pregnancy Outcomes}

Figure 4: Alternative Model with

Path Coefficients and T-Values

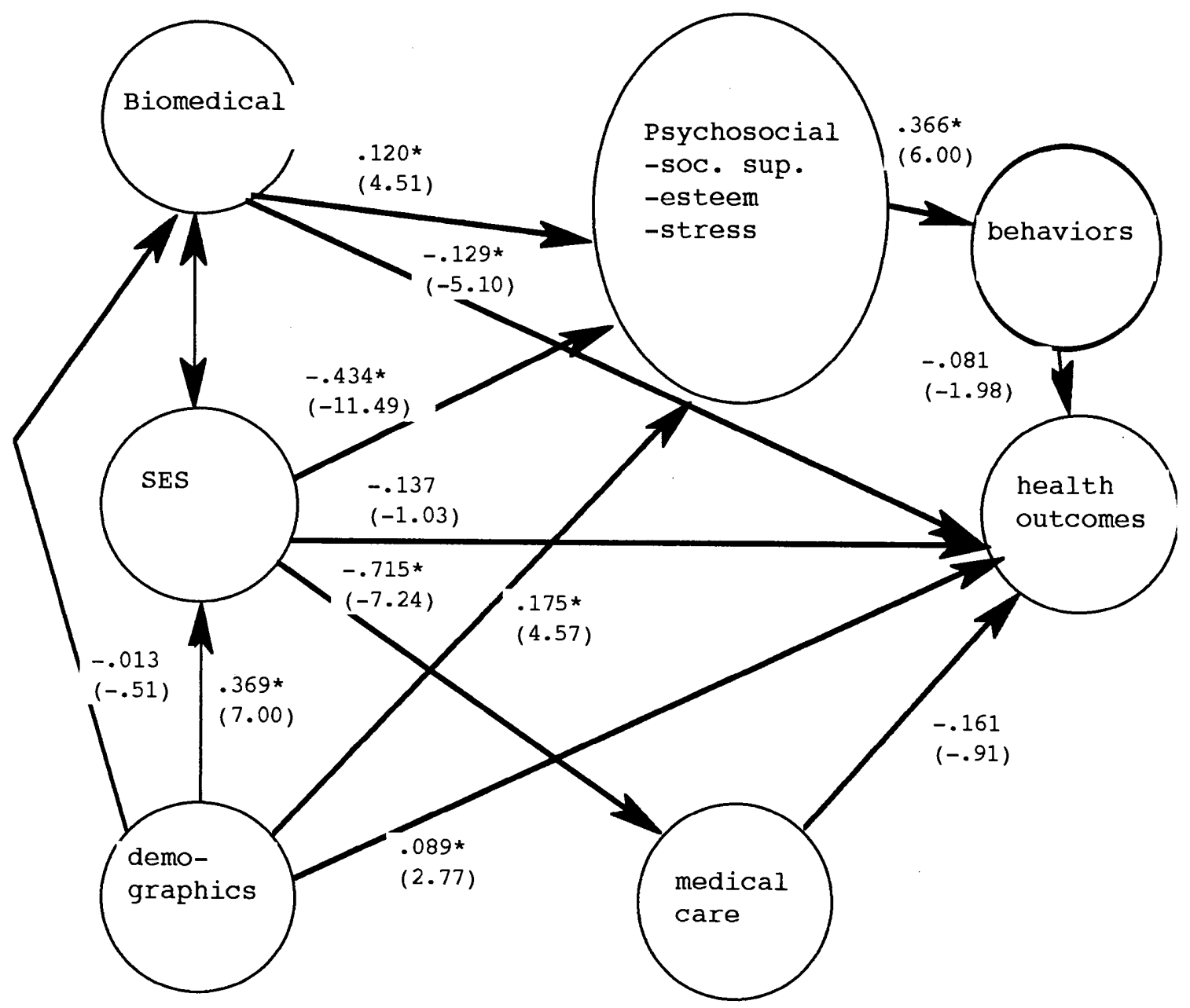

$t$-Values are in parentheses

* indicates significant paths

$\mathrm{n}=1134$ 
Pregnancy Outcomes

Chi squared was 2566.45 with 240 degrees of freedom for a ratio of 10.69. The adjusted goodness of fit was .877 and the root mean square residual was .066. These all indicate adequate fit, though not necessarily a better fit than the original model. The adjusted goodness of $f i t$ and root mean square residual are a slightly better fit in this model. The ratio of chi square to degrees of freedom also indicates a slightly better fit. Because of the large number of correlations involved, however, and the small size of the differences, the two models are virtually indistinguishable.

The range for standardized residuals was slightly better with a range of -21.1 to 21.9 Scores were normally distributed with $19.4 \%$ of the residual scores outside the $+/-3$ range.

The factor loadings for the measurement model can be seen in Table 9 . All variables significantly loaded on the specified factors.

The modification indices ran slightly higher for this model with a high index of 66.47 , followed by 65.49. Again there was one index in the 50's, and there were two in the $40 \mathrm{~s}$. These numbers are comparable to the original model, however when looking 
Pregnancy Outcomes

Table 9

Factor Loadings for the Alternative Measurement Model

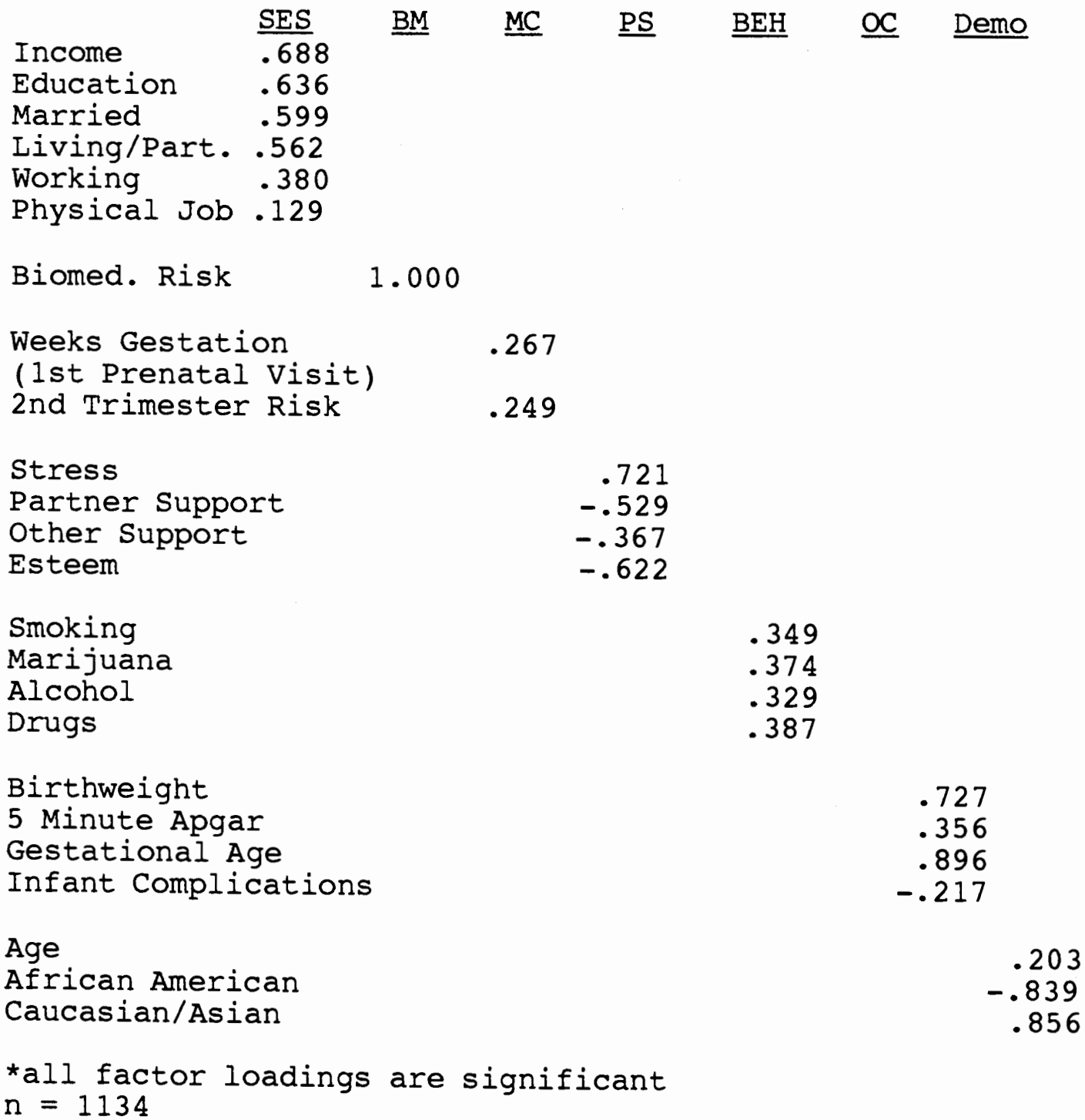


at the moderate indices, the original model had only 13 relationships above 20, while this one has 16 .

Path coeficients (betas) and $t$-values can be seen in Figure 4. Eight of 12 paths were significant. Three of the nonsignificant paths were the same as the previous model. These paths were from demographics to biomedical risk, from SES to outcomes, and from medical care to outcomes. In this model there was not a direct path from the psychosocial factor to outcomes; in place of this path, the path from psychosocial risk to behaviors was significant while the path from behaviors to outcomes was not.

The squared multiple correlation for the outcomes factor was .043 , so in this model only $4.3 \%$ of the variance in outcomes is explained by the other factors. The variance explained in medical care and the psychosocial risk factor is $51.1 \%$ and $18.8 \%$ respectively. The explanation in medical care is virtually the same as the previous model, since none of the changes affected it. The reduction in the amount of variance explained in the psychosocial factor is because part of the variance being explained in the earlier model was variance in the substance use items. The squared multiple correlation for behaviors is .113, 
so $11.3 \%$ of the variance in substance use can be explained by the psychosocial factor.

Overall these models were really indistinguishable in terms of fit. The adjusted goodness of fit, root mean square residual, and chi square to degrees of freedom ratio in the two models were too close to determine if one model really fit better than another.

\section{Regressions}

Regressions were run for each of the four outcome variables with time 1 psychosocial variables entered first and time 2 psychosocial variables entered second, to determine if the time 2 psychosocial variables accounted for outcomes after controlling for time 1 levels. The variables used in the regression were time 1 and time 2 for stress, partner support, other support, self-esteem, smoking, marijuana use, alcohol use, and drug use. The weight variables were not used for the regression as they were found non-significant in relation to the psychosocial variables in the confirmatory factor analysis. Tables 10-13 show the b's, betas, t's, p-values and SMC's for each regression. Only the birthweight variable was significantly predicted by the psychosocial variables $\left(R^{2}=.056\right)$. Marijuana usage at time 1 was significant, as was support from other at time 2 . No other 


\section{Table 10 \\ Regression for Birthweight}

Variables Entered First

\begin{tabular}{|c|c|c|c|c|}
\hline $\begin{array}{l}\text { Stress } \\
\text { Partner } \\
\text { Other } \\
\text { Esteem } \\
\text { Smoke } \\
\text { Marijuana } \\
\text { Alcohol } \\
\text { Drugs }\end{array}$ & $\begin{array}{r}\underline{b} \\
-12.34 \\
1.57 \\
1.36 \\
-3.29 \\
-29.06 \\
-386.12 \\
-101.44 \\
-361.11\end{array}$ & $\begin{array}{l}\frac{\text { beta }}{-.096} \\
.031 \\
.024 \\
-.029 \\
-.033 \\
-.0155 \\
-.041 \\
-.056\end{array}$ & $\begin{array}{r}\frac{T}{I} \\
-1.64 \\
.51 \\
. .44 \\
-.42 \\
-.42 \\
-3.08 \\
-.87 \\
-1.29\end{array}$ & $\begin{array}{l}\underline{P} \\
.10 \\
.61 \\
.66 \\
.68 \\
.67 \\
<.01 \\
.38 \\
.20\end{array}$ \\
\hline \multicolumn{5}{|c|}{ Variables Entered Second } \\
\hline $\begin{array}{l}\text { Stress } 2 \\
\text { Partner2 } \\
\text { Other2 } \\
\text { Esteem } 2 \\
\text { Smoke2 } \\
\text { Marijuana2 } \\
\text { Alcohol2 } \\
\text { Drugs } 2\end{array}$ & $\begin{array}{r}1.52 \\
-\quad 3.55 \\
-6.49 \\
6.29 \\
-57.75 \\
202.59 \\
46.81 \\
-\quad .17\end{array}$ & $\begin{array}{r}.011 \\
-.070 \\
-.011 \\
.052 \\
-.062 \\
.061 \\
.016 \\
.000\end{array}$ & $\begin{array}{r}.19 \\
-1.19 \\
-2.01 \\
.74 \\
-.80 \\
1.20 \\
.34 \\
-.00\end{array}$ & $\begin{array}{l}.85 \\
.23 \\
.04 \\
.46 \\
.42 \\
.23 \\
.74 \\
.99\end{array}$ \\
\hline \multicolumn{2}{|c|}{$\begin{array}{l}\text { Summary Statistics }(\mathrm{df}=16) \\
\text { Squared Multiple Correlation: }\end{array}$} & $\underline{1 s t}$ & \multicolumn{2}{|c|}{$\frac{\text { All Entered }}{.056}$} \\
\hline \multicolumn{2}{|c|}{$\begin{array}{l}\text { F: } \\
\text { Significance }\end{array}$} & \multicolumn{2}{|c|}{$\begin{array}{r}2.913 \\
.003\end{array}$} & $\begin{array}{r}2.006 \\
.011\end{array}$ \\
\hline
\end{tabular}

Note: all numbers are from the completed solution $\mathrm{n}=756$ 
Pregnancy Outcomes

Table 11

\section{Regression for Gestational Age}

Variables Entered First

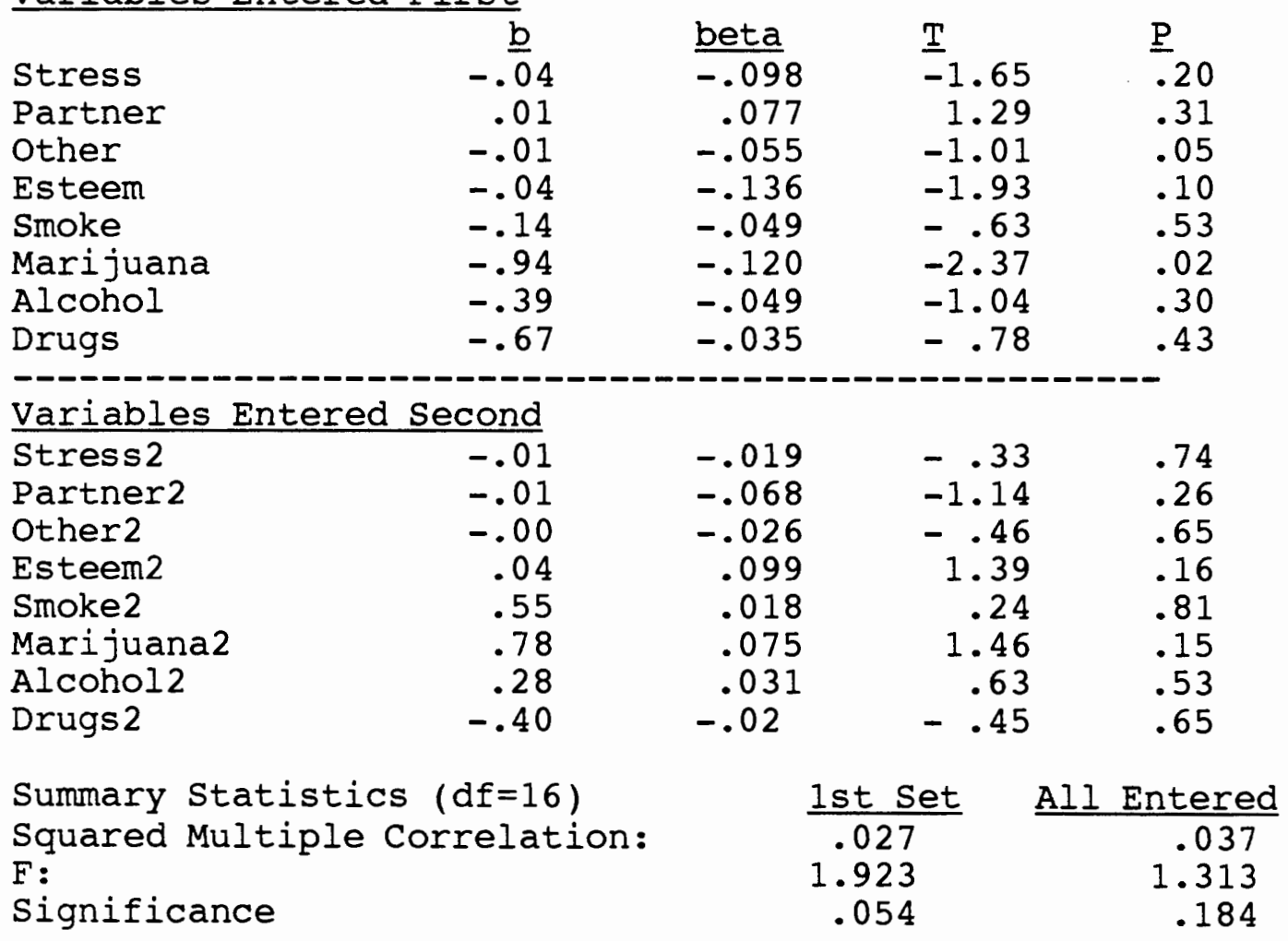

Note: All numbers are from the final solution. $\mathrm{n}=756$ 
Table 12

Regression for 5-Minute Apgar

Variables Entered First

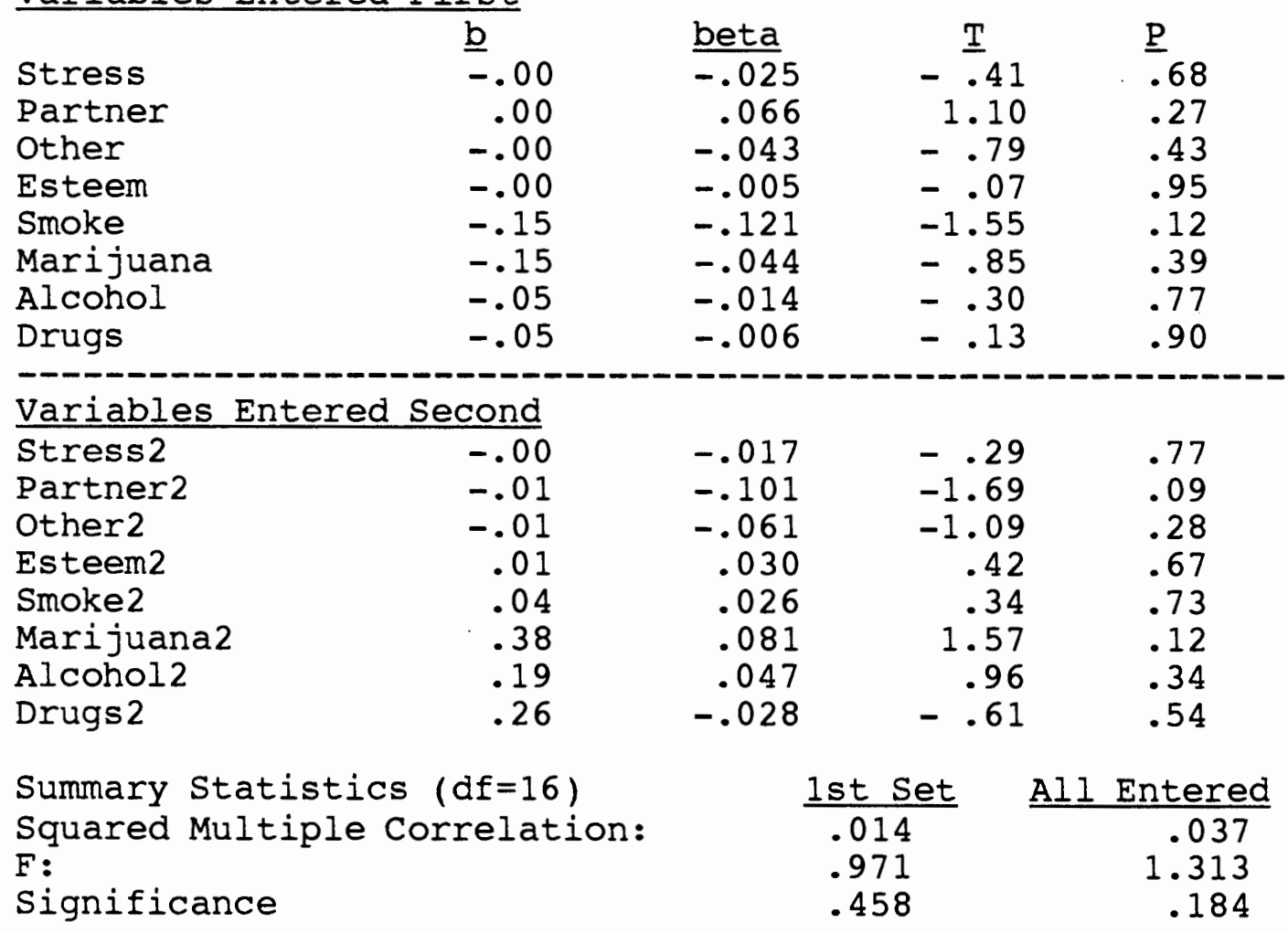

Note: All numbers are from the final solution. $\mathrm{n}=756$ 
Pregnancy Outcomes

76

Table 13

Regression for Infant Complications

Variables Entered First

\begin{tabular}{|c|c|c|c|c|}
\hline $\begin{array}{l}\text { Stress } \\
\text { Partner } \\
\text { Other } \\
\text { Esteem } \\
\text { Smoke } \\
\text { Marijuana } \\
\text { Alcohol } \\
\text { Drugs }\end{array}$ & $\begin{array}{l}\frac{b}{.01} \\
-.00 \\
.01 \\
.01 \\
.01 \\
.27 \\
-.04 \\
-.01\end{array}$ & $\begin{array}{l}\text { beta } \\
.028 \\
-.004 \\
.082 \\
.048 \\
.011 \\
.075 \\
-.013 \\
-.071\end{array}$ & $\begin{array}{r}\underline{T} \\
.46 \\
-.06 \\
1.42 \\
.65 \\
.14 \\
1.38 \\
-.026 \\
-1.52\end{array}$ & $\begin{array}{l}\underline{P} \\
.65 \\
.96 \\
.15 \\
.52 \\
.89 \\
.17 \\
.80 \\
.13\end{array}$ \\
\hline \multicolumn{5}{|c|}{ Variables Entered Second } \\
\hline $\begin{array}{l}\text { Stress2 } \\
\text { Partner2 } \\
\text { Other2 } \\
\text { Esteem2 } \\
\text { Smoke2 } \\
\text { Marijuana2 } \\
\text { Alcohol2 } \\
\text { Drugs2 }\end{array}$ & $\begin{array}{r}-.01 \\
-.00 \\
.00 \\
-.02 \\
.04 \\
-.38 \\
-.03 \\
-.04\end{array}$ & $\begin{array}{r}-.045 \\
-.006 \\
.019 \\
-.101 \\
.030 \\
-.076 \\
-.008 \\
-.046\end{array}$ & $\begin{array}{r}-.75 \\
-.09 \\
.32 \\
-1.34 \\
.36 \\
-1.40 \\
-.15 \\
-.94\end{array}$ & $\begin{array}{l}.45 \\
.93 \\
.75 \\
.18 \\
.72 \\
.16 \\
.88 \\
.35\end{array}$ \\
\hline \multicolumn{2}{|c|}{$\begin{array}{l}\text { Summary Statistics }(d f=16) \\
\text { Squared Multiple Correlation: } \\
\text { F: } \\
\text { Significance }\end{array}$} & \multicolumn{2}{|c|}{ 1st set } & $\begin{array}{l}\text { Entered } \\
.026 \\
.824 \\
.658\end{array}$ \\
\hline
\end{tabular}

Note: All numbers are from the final solution. $\mathrm{n}=756$ 
psychosocial variables made a significant contribution to predicting birthweight. Adding the time 2 variables also did not significantly increase the variance accounted for by the time 1 variables in any of the regressions.

\section{Discussion}

Overall Williams' model was not supported by the data. Three of the paths intended to explain variance in the health outcomes factor were non-significant and only $3.8 \%$ of the variance was explained by the two remaining significant paths. The alternative model and the regressions run on the psychosocial variables to predict the individual outcomes measures also did not explain the expected amount of variance in outcomes.

\section{Descriptive Information}

Descriptive data for the sample was similar to predictions. When compared to the overall population of women giving birth in the state of Oregon during the same time period, this sample was more likely to be unmarried and younger. This was expected, based on the clinic population sampled. Racially, this sample had a higher portion of African Americans, largely due to the oversampling of this group, but also in part due to the metropolitan, urban location of the clinics. It also had a lower portion of Hispanics compared to women who 
delivered babies statewide in 1994. The proportion of Asians was slightly lower and Native Americans was slightly higher (Oregon Vital Statistics Report, 1994). Other than the African American numbers, which were planned and caused by oversampling, other racial differences have to do with the sample being from the Portland Metropolitan area generally, and from county clinics specifically, while comparison birth numbers are for Oregon statewide. The percentages of minorities are also slightly higher for all ethnic minorities except Asians as compared to the Multnomah County Census (Oregon Social and Economic Characteristics, 1990).

The sample was also more likley to have reported using tobacco, alcohol, or illegal drugs during their pregnancy than Oregon women statewide. Rates of low birthweight were approximately the same (Oregon Vital Statistics Report, 1994). Though the sample described above is not necessarily representative of the overall population, it is representative of the group the study targetted: high risk, lower income women. This population is of interest because it is believed there is the most hope here for improving outcomes, but before this can be done, the reasons for current poorer outcomes must be understood. 
Pregnancy Outcomes

The directions of the relationships of the individual measures to each other were in the direction expected. The correlations in Tables 3 and 4 indicate the psychosocial measures have a solid relationship to each other, with all the Prenatal Psychosocial Profile items being significantly correlated in the expected direction, and all time 1 and time 2 variables significantly and positively correlated with themselves. These significant relationships speak well for the reliability of the measures.

\section{Test of the Measurement Model}

\section{Demographics}

The confirmatory factor analysis indicates the relationship of the individual measurement variables to the latent factors and the other measurement items. Table 4 presents the original confirmatory factor analysis measurement model. Table 7 presents the model with the insignificant variables removed. In the demographic latent factor, age loaded positively $(\lambda=$ .204), African American race loaded negatively $(\lambda=$ -.843), and Caucasian/Asian race loaded positively $(\lambda=$ .852), so increases in the demographic factor are related to increased age, increased likelihood of being Caucasian or Asian and decreased likelihood of being African American. Because African American race and 
Caucasian/Asian race are mutually exclusive, their opposite direction was expected. The fact that African American race loaded on the latent factor in the opposite direction as age (negatively) and Caucasian/Asian race loaded positively merely indicates that on average the African Americans in the sample are slightly younger than the Caucasians. It is important to note also, that though age loaded significantly on this factor, the factor loading was much smaller than those of the race variables, so while this factor is called demographics, it really more closely indicates a race factor.

$\underline{\text { SES }}$

In the SES latent factor, all variables loaded positively. Higher SES in this sample is associated with higher income $(\lambda=.687)$, higher education $(\lambda=$ $.630)$, being married $(\lambda=.609)$, living with a partner $(\lambda=.567)$, working $(\lambda=.366)$, and work involving physical labor $(\lambda=.120)$. The only surprise here is that physical labor is associated with higher SES, however the loading was only .12, and the percentage of women whose work is physical was $9.4 \%$. In this population with an average of only 12 years education, it is possible that physical jobs, such as nursing, are associated with higher income, and more education, and 
therefore higher SES. The other SES variables were expected to load positively on SES based on past findings (e.g. Williams, 1990; House, et al., 1990).

\section{Biomedical Risk}

The biomedical risk measure was the only indicator of the biomedical factor, so it was a perfect indicator $(\lambda=1.00)$. Higher scores were associated with a greater number of biomedical risks going into the pregnancy.

\section{Medical Care}

The weeks gestation of the first prenatal visit loaded positively on the medical care factor $(\lambda=.121)$, so a high score on the medical care factor was associated with later prenatal care. Number of prenatal visits did not significantly load on this factor $(\underline{t}=-.397)$ and had an associated high standard error so it was dropped. The second trimester biomedical risk assessment was negatively associated in the first confirmatory factor analysis $(\lambda=-.014)$, however when the number of prenatal visits was dropped, the direction of biomedical risk changed $(\lambda=.240)$ indicating that higher risk is associated with a higher score on medical care. This pattern is supported by the literature (Lia-Hoagberg, et al., 1990). 
Pregnancy Outcomes

\section{Psychosocial}

In the psychosocial factor stress loaded positively $(\lambda=.707)$. Support from partner, support from others, and self-esteem were all negatively associated with this, with factor loadings of $-.530,-.366$, and -.618 respectively. All the substance items were positively associated, (smoking $\lambda=.232$. marijuana $\lambda=.132$, alcohol $\lambda=.102$, and drugs $\lambda=.112$ ) so higher scores on the psychosocial variable indicate higher stress, lower support of both kinds, lower esteem, and higher use on all substances. With this in mind, it might be better called the psychosocial risk variable. It should be noted that the strongest indicators on this factor are stress and self-esteem; followed by partner support. By comparison, the substance use measures are much less related to the overall factor.

The weight measures did not load significantly on the psychosocial factor $\underline{t}=1.609 ; \underline{t}=.026)$. The Curry and Wall study which provided the data for this research considered the weight measures as medical risk variables. In this research, the weight measures were considered indicators of the psychosocial factor because it was believed weight was an indicator of nutrition and exercise which are behavior variables. However, the data did not support the weight measures 
Pregnancy Outcomes

loading on the psychosocial factor. It was determined that rather than lose the information the weight variables provide, that they should be returned to their respective biomedical risk measures. Therefore, beginning weight was returned to the biomedical risk measure, and weight gain was returned to the second trimester risk assessment. After removing the weight variables, the direction of the relationships of the remaining psychosocial variables to the latent factor remained the same.

\section{Outcomes}

In the outcomes latent factor birthweight loaded positively $(\lambda=.731)$ and higher birthweight was associated with higher five-minute Apgar scores $(\lambda=$ $.356)$, higher gestational age $(\lambda=.891)$, and fewer infant complications $(\lambda=-.219)$. Delivery complications did not significantly load on the outcome factor and so the variable was dropped.

\section{Test of William's Model:}

\section{Demographics}

The relationship of the latent variables to each other can be seen in Figure 3 and is as follows: The demographic factor is associated with higher SES, higher psychosocial risk, and better outcomes. Since the race indicators are much stronger indicators of the 
demographic factor than age, this means that being Caucasian or Asian and not being African American increases SES $(\beta=.369)$, increases psychosocial risk ( $\beta$ $=.193)$ and increases positive outcomes $(\beta=.080)$. The positive relationship to psychosocial risk contradicts some of the literature in that it indicates that being Caucasian or Asian puts people at higher psychosocial risk. Literature in the area shows that being an African American predisposes people to higher stress. For example Ulbrich, Warheit, and Zimmerman (1989) found that though lower SES whites suffered greater distress in reaction to economic stressors, lower SES blacks suffered greater distress from life events stressors. One possible explanation for the direction of this relationship is that SES is actually the factor which accounts for the variance in psychosocial variables seen in previous studies. The remaining relationship between demographics and psychosocial risk represents a different type of relationship. There is however, literature supporting that Caucasians are more likely to use alcohol and drugs (Parker, et al., 1995). It has also been found that African American women are more likely to be satisfied with the maternal support they receive, and are less physiologically affected by the absense of spousal support (Shumaker \& Hill, 1991). 
Pregnancy Outcomes

These studies support the direction of the relationship found in the current study.

Older people having better outcomes $(\beta=.080)$ contradicts some of the literature, though both older and younger women have higher prenatal risk (Curry, $1991)$ and in this sample fewer than 5\% of the women are over age 35, while $36 \%$ are age 20 or younger. Race is also a much stronger indicator than age for the demographic factor and race is specifically related to birthweight. As Moore (1988) noted, in every age group black women are 45\% more likely to deliver a low birthweight baby.

\section{$\underline{\text { SES }}$}

Higher SES is strongly associated with lower medical care scores $(\beta=-.716)$ which means earlier care and fewer risks. Of note is that SES alone is responsible for more than $50 \%$ of the variance in the medical care measures. This relationship is supported by the literature (e.g. Poole \& Carlton, 1986; \& LiaHoagberg, et al., 1990). Higher SES is also associated with lower psychosocial risk $(\beta=-.456)$, which supports the findings of Adler, et al (1994) and McLeod and Kessler (1990) among others. The path coeeficients here, and the variance accounted for by the SES factor 
are among the most significant in the current research. These relationships merit closer examination.

Biomedical Risk

Higher biomedical risk is associated with higher psychosocial risk $(\beta=.125)$ and poorer outcomes $(\beta=$ -.132). Higher biomedical risk leading to higher psychosocial risk contradicts some of the literature. In Hickey, Rakowski, and Julius' (1988) literature review on aging people and health practices, they found that as people became more disabled, their health protective behaviors improved. However, higher risk life styles may be stable over time. People who have had higher stress and poorer behaviors and resources may have had medical complications caused by this and so are currently in an even higher risk position. The correlations on all time 1 and time 2 psychosocial measures were significant implying longer term patterns in terms of resources, stress level, and behaviors. Further research would be necessary to determine if this relationship is truly one direction rather than a correlation.

The direction of higher biomedical risk being associated with poorer outcomes is not surprising. Curry and Wall (1991) note that biomedical risks have traditionally been measured for the specific purpose of 
predicting adverse outcomes in pregnancy. Although the predictive ability of these measures is not very high, these measures do better than anything else available.

\section{Insignificant Paths}

Four paths in the model were insignificant. The first is the path from demographics to biomedical risk. The literature here is sparse. Some of the risk factors are related to race, for example chronic hypertension is a risk factor mentioned in the biomedical risk assessment, and is more common among African Americans (Dressler, et al., 1986). Several of the risk factors are also related to previous pregnancies, and the older a person is, the more likely she is to have had multiple pregnancies, thereby increasing the chance of having risk factors. It could be that age would cause the direction of this relationship to run in one direction and race in a different direction. The overall effect would be to supress the overall relationship of demographics to biomedical risk. An examination of the zero order correlations confirms that age has the strongest positive correlation with the biomedical risk measure and that the African American race variable is also positively correlated and the Caucasian/Asian race variable is negative, so age would lead the path in one 
direction and both race variables would indicate another. Age also is not as strong an indicator of the demographic variable as either race variable, and the relationship of each race variable with the biomedical risk measure is low. Since the relationships of the race measures to biomedical risk is small, a power problem may be at play. If African American race is related to certain risks, but incidence of those risks is low, perhaps a larger sample size, or a greater portion of African Americans would show this.

Three of the paths leading to outcomes were also insignificant. The first insignificant path is from SES to outcomes, which contradicts the majority of the literature (e.g. Williams, 1990, Poole \& Carlton, 1993). The low incidence of poor outcomes and low birthweight reduces the power of the study, making it more difficult statistically to pick up effects on outcomes. In the majority of women (58.8\%) not a single poor outcome was present. Infant complications was the most common poor outcome reported (38.3\%) and in those that had infant complications the most prevalent was Meconium staining (20.9\% of total sample), which is an indicator of potential, not actual, fetal distress. Fewer than $10 \%$ of the women studied had more than one poor outcome. If the power 
of the study was increased, perhaps a significant relationship would be found. Another possibility is that the effect of SES on health outcomes is an indirect effect through psychosocial risk and medical care, though the insignificant paths from these variables to outcomes does not support this in the current study.

The measures of SES have effects which run in differing directions. Income and education, for example, are known to be related to positive birth outcomes (Poole \& Carlton, 1993), while it is possible that working and work involving physical labor may have a negative impact in relation to pregnancy outcomes. Recall that all of these variables loaded positively on the SES factor. To test the notion that the SES variables were working in different directions, regressions were run with the SES variable predicting the individual outcomes measures. The only outcome measure which was significantly predicted by the SES measures was birthweight. It was confirmed that two of the variables had negative coefficients, while four had positive; however the two negative coeficients, education and physical work, were not significant. For a closer look, the zero order correlations were examined. For birthweight, all the correlations with 
SES variables were positive except physical work which was 0. For Apgar score, all the correlations were positive except physical work. For gestational age, three were positive, three were negative, but all were low. The three negative coeficients were income, living with a partner and physical work. For infant complications all were negative except living with a partner which was 0 and physical work which was positive. So there is not strong evidence that the relationships of the SES variable counteracted each other.

The study for which these data were collected was designed to obtain a sample of low SES women, decreasing the variance in this measure. It is likely that the homogeneity of the population on SES and the low incidence of poor outcomes contributed to the insignificant relationship of SES with outcomes by reducing the power of the relationships.

For covariance structure modelling multivariate normal distribution of variables is assumed, meaning that while each individual variable doesn't need to be normally distributed, the multiple measures indicating the factors should be. Outcomes in this study were slightly skewed for each outcome measure. Birthweight was skewed toward low birthweight, Apgar toward low 
Apgar, gestational age toward prematurity, and infant complications toward greater complications. In each case the less desired result had the longer tail, with the mean resting close to the maximum. The impact of this kind of distribution is to reduce the power of the findings.

The path from medical care to health outcomes is not significant. This could be due to low statistical power and/or the measures used to specify medical care. Medical care was not a factor of interest in the the Curry and wall study, and so the medical care measures were not taken with the intention of using them for covariance structure modelling. While the weeks gestation of the first prenatal visit and number of second trimester risks are related to outcomes (LiaHoagberg, et al., 1990), they are probably not sufficient to specify the medical care factor. They are also likely to have had their portion of the outcomes' variance previously explained by the biomedical risk or other variables. Developing the medical care variable more fully is likely to improve the strength of this relationship and hopefully indicate which components of medical care are important to improving outcomes. 
The fact that medical care was not a factor of interest in the original study explains some of the complications with the measurement component of the medical care factor. While in the end, weeks gestation of the first prenatal visit and the second trimester biomedical risk significantly loaded, a third variable had to be dropped. The current study could be improved if a more careful set of measures were included to indicate medical care. Institutional practices, such as waiting times, scheduling problems, and seeing the same provider each time; attitudes about prenatal care and prenatal care providers; and satisfaction with medical care choices are all variables which Curry (1990) mentions as important to obtaining adequate prenatal care. In addition, Lia-Hoagberg et al. (1990) found that barriers to care predicted over $50 \%$ of the variance in the use of prenatal care. The barriers discussed were structural, psychosocial and sociodemographic. The variables they found important which have not been addressed anywhere else in this study are finding time for appointments, child care for other children, and transportation to appointments. Trouble with each of these variables was significantly different for women who received inadequate prenatal care versus women who received adequate or intermediate 
levels of care. Barrier measures would be good inidicators of one aspect of care and also perhaps indicate a place for interventions. Another variable that could be of interest is the time between seeking care and actually receiving it. Meachen and Kelley (1991) found that the greater the time between sought care and received care, the greater the likelihood of low birthweight. Curry and wall (1990) noted in their proposal that one of the reasons for admitting women into the study as late into their pregnancy as they did, is that waiting for appointment openings at the county clinics can be long. In this particular population, a measure of time discrepancy may be an important one.

The final insignificant path was from the psychosocial risk factor to outcomes. While it was expected that this variable would only explain a small portion of variance after the medical measures and SES, it was still expected to be significant.

The psychosocial measure was not designed for a test of Williams' model. Curry and Wall were interested in a much more specific role for support and stress, while the Williams' model uses these resources in a much more general way. The original study was also not interested in behaviors per se, but only 
substance abuse behaviors, while Williams' model referred to a fuller spectrum of behaviors.

One possible problem for the current study may be that all measures in the psychosocial risk assessment are self-reported. While the majority of the literature utilizes self-reported measures of support (Uchino, Cacioppo, and Kiecolt-Glazer, 1996), there is literature suggesting that some of the objective measures of support are more strongly related to health enhancement (Gottlieb \& Green, 1984). Uchino and colleagues also suggest that behavioral data from laboratory studies could enhance our understanding of social support in the physiological process.

The support variables in the Curry and Wall study measure satisfaction with sources of support. People with poor support, but no basis for comparison may be satisfied at much lower levels, or with unhealthy kinds of support. The Curry and Wall study looked at this possibility by examining high support satisfaction in relation to substance use (giving support by or along with using substances together). Williams' model had no control for this possibility with the current measures. There is also no distinction about who the "others" that support is received from are and their importance to the women in the study. Shumaker and 
Hill (1991) for example found that while men needed only one support person (a spouse) to gain the positive health effects of social support, women needed more varied sources and more frequent interaction. It was also found that for black women, support from their mother was important to pregnancy outcomes, while for white women, some forms of maternal support were actually negative in terms of pregnancy outcomes. Uchino et al. (1996) reviewed the social support literature and found that type of support was crucial, with emotional support having the greatest impact on physiological functioning. In contrast, Collins et al. (1993) found that in predicting pregnancy outcomes, instrumental support was more important than emotional support. In a Franks et al. (1992) study, three measures of support were positively correlated with depressive symptoms, and one (family critisism) was negatively associated. However, when the support measures were used to predict depressive symptoms in a regression, family criticism and emotional involvement of the family both had positive predictive value. In the same study however, emotional involvement of the family positively predicted healthy cardiovascular behaviors. Many of the above studies mention different support needs in different situations; perhaps the 
support assessment tool for the current study should incorporate questions relating specifically to pregnancy, health, or health related activities. Jung (1990) found that health specific support questions better predicted complying with doctor recommended behaviors with regards to high blood pressure than global support measures. Uchino, et al. (1996) suggest that the positive and negative components of support should be examined separately as the negative influence is independent of the positive. In the future, perhaps objective and subjective measures should both be used, as well as specifying the types of support being received. The social support literature has a broad spectrum of possibilities, but measures which include both actual support and network structure, (Haines \& Hurlbert, 1992) and measures which allow for the negative component of support (Franks, et al., 1992) are important aspects that should be included in future research using Williams' model. A study which included this complexity of social support would be more telling in terms of which component has the larger impact. This is especially true for a model like williams' which speaks of psychosocial variables in such broad terms. 
The stress measurement tool covers several pertinent areas, however for Williams' model perhaps an overall perceived stress measure is needed. An overall single rating of the stress level a person feels, or an item analysis to determine which items may need to be weighted more heavily would be informative for the current study. Lederman (1995) brings up another possibility. She discusses stress as being divided into eustress and distress and suggests that there is a level at which stress is positive and needed for growth and development. With this in mind, it is possible that a scale which indicates $0=$ no stress, misses the possible positive component for stress. Even with a 4 point scale where 1 is optimal, the relationship of higher stress is clouded because of the possibility that stress has both a positive and negative impact. There may also be some difficulties with the behavior measure, as there would be with any measure of this type. The behaviors, while confidential, were regarding substance use and so there is a high likelihood of underreporting. Only $8 \%$ of the women surveyed reported using any alcohol or marijuana. The wording of the questions also may have contributed to underreporting of irregular use. Women were asked how much of the substance are you using these days, and the 
answer choices imply regular use, even if the choices include low quanties. Perhaps infrequent binges were under-reported because the women felt they didn't "do it regularly" so did not choose "one per day" (alcohol or cigarettes) or "one per week" (marijuana). There is also the possibility that women did not entirely believe results would be confidential. People who have had contact with the Child Services Division in the past may fear retribution if they are using substances while pregnant and may fear answering accurately. The concept of health behaviors for the current study should include a much broader range of behaviors than just substance use items. Williams specifically mentions weight maintainance, physical exercise, and getting enough sleep, in addition to substance use. Substance use was the only behavior set really examined in the current study because other behavior items were not measured. In terms of a pregnancy, eating habits and exercise are both known to have an effect. The Public Health Service Expert Panel on the Content of Prenatal Care (1989) determined that appropriate prepregnancy weight and optimal nutrition during pregnancy are associated with improved infant birthweight and reduced infant morbidity and mortality. Another behavior affecting pregnancy outcomes is sexual 
behavior, as cervico-vaginal infections are related to many causes of premature labor (Gravett, 1984). If women were educated to be checked for infections when they had a new partner, or better, to have their partner checked before sexual relations, incidence of infection and the impact of undiagnosed infections on pregnancy outcomes could perhaps be reduced. The Iiterature indicates that behaviors are complex, but in order to determine behaviors' role, a broad range should be examined.

Additional psychosocial factors may also be relevant which were not measured here. Williams' original model mentioned control, which was not measured in this sample, but has been shown to be related to position in the social structure and to influence health behaviors (Calnan, 1989). Coping, hardiness, and optimism may also be psychosocial components which need examining. Nowack (1989) found that coping style was predictive of physiological and psychological distress and that cognitive hardiness predicted psychological distress. In a literature review on the role of hardiness, Wiebe and Williams (1992) found that at least some components of hardiness were valuable in stress reduction. Optimism is another variable which has been shown to influence 
psychological and physical well-being (Scheier \& Carver, 1992). The authors note that the mechanism here is through more adaptive responses to stress and a positive influence on health behaviors. Uchino et al. (1996) in their review on social support discuss personality traits, specifically neuroticism, extroversion, and hostility, as affecting physiological health. The first two appear related to subjective measures of well-being, while hostility is related to objective measures. They note that many personality traits also have an indirect affect by influencing long-term, stable measures of social support.

Overall, being older and Caucasian/Asian increases SES, and higher SES and lower biomedical risk reduce psychosocial risk. Higher SES leads to earlier medical care and fewer developing risks, but the only factors which significantly affect outcomes are biomedical risk and demographics. Unfortunately neither of these factors has alterable components indicated in this model, so improving outcomes is a mystery.

The covariance structure model, while fitting the data, explains only $3.8 \%$ of the variance in the outcomes measure. This is lower than past studies which didn't include psychosocial variables. Wall, et al. (1989) found that with a biomedical model he could 
explain $7 \%$ of the variance in low birthweight occurrence. It was hoped that the psychosocial measures would improve the variance accounted for in outcomes. With this in mind, another model was tested in which behaviors were a separate factor from the psychosocial factor.

\section{Alternative Model}

In this model demographics were associated with higher SES, higher psychosocial risk, and better outcomes. Of note here is that demographics are still related to psychosocial risk when the substance items are removed. Being older and Caucasian or Asian predicts higher stress, lower support and lower esteem. on examining the zero order correlations of the demographic variables with the psychosocial variables, it was discovered that the relationship of esteem to the demographic variables is strongest and the direction of the relationships would predict Caucasians/Asians having lower resources. Being African American is more highly and positively correlated with esteem $(r=.081)$ than any other pair of relationships among these two factors. Being Caucasian/Asian is negatively correlated with esteem ( $r$ $=-.057)$. The stress and other support correlations were all smaller than these. The partner support 
correlations would have predicted the path between demographics and psychosocial risk to be negative, with older and Caucasian/Asian people receiving more satisfactory partner support. However, the stronger correlations for the esteem variable determined the direction of this path.

Higher SES predicts earlier medical care and fewer second trimester risks $(\beta=-.715)$, and fewer psychosocial risks $(\beta=-.434)$. Again, it is of note how strongly the SES measures influence the medical care factor and the psychosocial risk factor. These are powerful relationships. Future research should focus on why these relationships are so strong and whether there are mechanisms that can be used to alter the relationships and therefore improve medical care and reduce the psychosocial risks of lower SES people. Higher biomedical risk is associated with higher psychosocial risk $(\beta=.120)$ and poorer outcomes $(\beta=$ -.129). Higher psychosocial risk is associated with more substance use $(\beta=.366)$.

Insignificant Paths

Again, four of the paths were insignificant; the first three are the same first three paths as were insignificant in the previous model: demographics to biomedical risk, SES to outcomes, and medical care to 
Pregnancy Outcomes

outcomes. There is not a direct path from psychosocial risk to outcomes in this model. Of the two paths that take its place, one is significant and one is not. Psychosocial risk is significantly related to substance use, but substance use is not significantly related to outcomes. The t-value on this is $-1.98(-2.0$ would have been considered significant) and it is believed that a more varied, or more objective behavior measure may improve this relationship. As discussed in the previous section, substance abuse behaviors were the only behavior items measured. Adding measures to account for eating, sleeping, and exersize habits could perhaps push this factor across the significance barrier.

The variance in outcomes explained by this alternative model is still only 4.38 , which is virtually indistinguishable from Williams' model since differences in models which have different latent factors can't be tested statistically. The structural model overall fits about the same as Williams original model. It is also believed that to truly test a model which includes a separate behavior factor, a research review should be conducted to explore the theoretical relationship of the behaviors factor to the other latent factors in the model. None of the modification 
Pregnancy Outcomes

indices related to the behavioral factor were particularly high, though the literature indicates that perhaps demographics are related to behaviors (Dean, 1989). Dean's study also implies that gender should be the strongest demographic in this relationship as compared with age and marital status. There is no variation in gender in our sample. With this in mind future studies which have variation in gender may want to examine this as a possible path.

The second model has a slightly better adjusted goodness of fit (.877 vs. .871) and a slightly better root mean square residual (.066 vs . .068) and a slightly better chi square/degrees of freedom ratio (10.69 vs. 11.15). Overall both models fit the data adequately, but because of the low variance explained in outcomes, both have little utility in directing us how to improve health outcomes. Demographics and biomedical risk going into a pregnancy are not variables for which interventions can be designed and so are not helpful in efforts to improve pregnancy outcomes. The paths from the medical care and psychosocial factors, which have alterable components or potential for intervention, did not have significant relationships. However, the relationship from SEs to outcomes also was not significant, so at least 
according to this study, poorer people aren't doomed to poorer outcomes.

\section{Hierarchical Regressions testing the Relationship of} the Psychosocial Measures to the Outcomes Measures The regressions did little more to shed light on ways to improve birth outcomes. Only the regression predicting birthweight from psychosocial variables was significant (Table 10). In no case were time 2 variables significant after controlling for time 1 . This indicates that changes in the psychosocial variables during the pregnancy do not significantly alter outcomes after controlling for initial levels.

In the birthweight regression, marijuana use at time 1 and support from others at time 2 are the two strongest variables. Both have a negative relationship, with more marijuana use and more support from others decreasing birthweight. It seems illogical that more support leads to lower birthweight. Past findings have shown support to be related to lower rates of low birthweight (Zimmer-Gemback, \& Helfand, 1996). However, support at time 1 is positively related to birthweight and support at time 2 after controlling for time 1 support is negatively related. The variance explained by the second support measure is the part of support at time 2 which is unrelated to 
support at time 1. This component of support has a negative impact on birthweight. This could be due to partners giving inappropriate forms of support such as trying to control what a woman eats and does while she is pregnant. In this regression, only $5.6 \%$ of the variance in birthweight is explained by the psychosocial variables; however, this is a greater portion than the amount explained by the covariance structure models for the outcomes measures.

\section{Limitations of this study}

The most obvious limitation of this study is that the data were not collected for the purpose of testing Williams' model. The study was designed to test a biopsychosocial model which did not include medical care measures and the demographic and socioeconomic measures were looked at as the single factor of sociodemographics.

There is also very low incidence of low outcomes with fewer that $10 \%$ of births having more than one poor outcome. While this is good as the desired goal is to reduce this even further, it creates difficultly for studying the causes of poor outcomes. The low incidence reduces the statistical power of models meant to predict poor outcomes. The way to improve this power problem is to increase incidence of poor outcomes 
in the study. This could be done by studying even higher risk populations or by increasing the sample size of the whole study. For Williams' model an increase in sample size would be more appropriate, as the variation in the other risk variables is required to understand the overall picture.

There is also the power problem related to the nonnormal distribution of the overall outcomes factor. In a factor such as this, there is a natural maximum for the variables of birthweight (only two babies were over 10 pounds) and gestational age (babies are typically induced if not born by 42 weeks) and an imposed maximum of 10 on the Apgar measure. Yet the mean of all three of these is very close to the maximums, and the goal is for the mean to fall even closer. Medical care on the other hand is saving smaller and earlier babies all the time, creating a tail toward the other end, so the skewness of these variables cannot be avoided. It is an issue however which should be recognized in the planning stages of future studies and accommodations for this should be made,

Because the sample was collected from county clinics in the Portland, Oregon metropolitan area, results cannot be said to be representative of the United States, or even the general population in 
Pregnancy Outcomes

Portland. People who use the county clinics are more likely to be medically indigent, or poor, and tend to be concentrated in the more urban areas of the city. This limitation should be seen not as a downfall of the current study, but rather as a side effect of examining any specific population. This particular population is of interest because of the higher level of risk factors they are subject to and because it is believed that the greatest good can come from understanding and improving the circumstances related to the health of these women.

It should also be noted that with this study, the model has only been shown to fit in the case of pregnancy outcomes. With general health, the model may do worse or better at explaining the variance in outcomes. There also may be varying levels of fit and utility with other specific medical situations, such as cancer or diabetes.

The fact that the model fits and allows for the complexity of the relationships indicates that work should be done to design measures specifically to test this model in various situations. It is hoped that with those improvements, more variance in the outcomes can be explained and, intervention points can be discovered and tested to improve the health of lower SES people. 
Pregnancy Outcomes

\section{Summary and Conclusions}

In summary, the measurement model was successful. The measures were related to each other in such a way as to cluster into latent factors resembling those discussed in Williams' model.

with regard to the covariance structure model, Williams' model fit the data, supporting the first hypothesis. That is from a statistical standpoint, the model met the rough criteria that a covariance structure model requires. However, from a practical standpoint, the model did not prove useful, nor did the alternative model. The reasons for this lack of utility are the low variance explained in outcomes, which is the purpose of utilizing a biopsychosocial model. Also, none of the paths which would indicate possible interventions to improve outcomes was significant.

The regression analysis also did not support the second hypothesis. The psychosocial variables did significantly predict birthweight, though not the other outcomes. However, the time 2 variables did not significantly increase the variance explained by the time 1 variables.

Although it was discouraging to have so little of the variance in outcomes explained, this study makes a 
Pregnancy Outcomes

strong case for the power of socioeconomic status and the influence it has on both psychosocial resources and medical care. The medical care factor in particular, could prove to be a place where interventions to improve the health of lower SES groups is possible. As noted earlier, the literature indicates places where changes in the measures might be useful so that future studies may use this model. By clarifying how psychosocial variables and medical care should be conceptualized and measured for this specific model, perhaps the impact of these factors on outcomes could be understood. A logical starting place for examining these solutions is with general health as the outcome, then models for specific cases could be altered accordingly.

The results of this study don't indicate immediate answers, however, they do provide enough evidence to warrent further examination of Williams' model, or some variation of it. The study also supports how important it is to continue examining possible mechanisms for the relationship of SES with psychosocial variables, medical care and health in general. 
Pregnancy Outcomes

\section{References}

Adler, N.E., Boyce, T., Chesney, M.A., Cohen, S., Folkman, S., Kahn, R.L., \& Syme, S.L., (1994). Socioeconomic status and health: the challenge of the gradient. American Psychologist. $\underline{49}(1) \cdot 15-24$. Aldwin, C.M., \& Revenson, T.A., (1986). Vulnerability to economic stress. American Journal of Community Psychology. 14 (2). 161-175.

Allison, K.R. (1991). Theoretical issues concerning the relationship between our perceived control and preventative health behaviour. Health Education Quarterly. $\quad \underline{6}(2) \cdot 141-151$.

Antonovsky, A., (1967). Social class, life expectancy and overall mortality. Milbank Memorial Fund Quarterly. $\quad \underline{45}(2) .31-73$.

Belle, D., (1990). Poverty and women's mental health. American Psychologist. 45(3). 385-389.

Berkman, L.F., \& Breslow, L., (1983). Health and Ways of Living: The Alameda County Study. New York. Oxford University Press.

Bobak, I.M., \& Jensen, M.D., (1991). Essentials of Maternity Nursing. Third edition. Mosby Year Book, Inc. St. Louis, MO. 
Pregnancy Outcomes

Briones, D.F., Heller, P.I., Chalfant, H.P, Roberts, A.E., Aguirre-Hauchbaum, S.F., \& Farr, W.F. Jr., (1990). Socioeconomic status, ethnicity, psychological distress and readiness to utilize a mental health facility. American Journal of Psychiatry. $147(10) \cdot$ 1333-1340.

Brown, M.A., (1986). Social support, stress, and health: a comparison of expectant mothers and fathers. Nursing Research. 35. 72-76.

Calnan, M., (1989). Control over health and patterns of health related behavior. Social Science and Medicine. $\underline{29}(2) \cdot 131-136$.

Cockerham, W.C., Kunz, G., Leuschen, G., \& Spaeth, J.L., (1986). Symptoms, social stratification, and self-responsibility for health in the United States and West Germany. Social Science and Medicine. 22 (11). 1263-1271.

Cockerham, W.C., Leuschen G., Kunz, G., \& Spaeth, J.L., (1986). Social stratification and selfmanagement of health. Journal of Health and Social Behavior. $27(3) \cdot 1-14$. 
Collins, N.L., Dunkel-Schetter, C., Lobel, M., \& Scrimshaw, S.C.M., (1993). Social support in pregnancy: psychosocial correlates of birth outcomes and postpartum depression. Journal of Personality and Social Psychology. $\quad \underline{65}(6) \cdot 1243-1258$.

Cooper, M.L., Russell, M., Skinner, J.B., Frone, M.R., \& Muder, P., (1992). Stress and alcohol use: moderating effects of gender, coping, and alcohol expectancies. Journal of Abnormal Psychology. 101(1). $139-152$

Cozzarelli, C., (1993). Personality and selfefficacy as predictors of coping with abortion. Journal of Personality and Social Psychology. $\underline{65}(6)$. $1224-1236$.

Curry, M.A., (1990). Factors associated with inadequate prenatal care. Journal of Community Health Nursing. $\underline{7}(4) \cdot 245-252$.

Curry, M.A., \& Wall, E., (1991). Proposal for study: biopsychosocial model to predict LBW/pregnancy outcomes.

Dean, K., (1989). Self-care components of lifestyles: the importance of gender, attitudes and the social situation. Social Science and Medicine. $\underline{29}(2)$. $137-152$. 
Dressler, W.W., Dos Santos, J.E., \& Viteri, F.E., (1986). Blood pressure, ethnicity and psychosocial resources. Psychosomatic Medicine. 48(7) • 509-519.

Elliott, S.J., (1995). Psychological stress, women, and health health: a critical review. Social Science and Medicine. $\quad \underline{40}(1)$. 105-115.

Ensel, W.M. \& Lin, N., (1991). The life stress paradigm and psychological distress. Journal of Health and Social Behavior. $32(12)$. 321-341.

Ernest, J.M., Michielutte, R., Meis, P., Moore, M.L., \& Sharp, P., (1988). Identification of women at high risk for preterm-low-birthweight births. Preventative Medicine. $\quad \underline{17}(1)$. 60-72.

Fisher, J.D., (1988). Possible effects on reference group-based social influence on AIDS-risk behavior and AIDS prevention. American Psychologist. $\underline{43}(11) \cdot 914-920$.

Franks, P., Campbell, T.L., \& Shields, C.G., (1992). Social relationships and health: the relative roles of family functioning and social support. Social Science and Medicine. $\quad 34(7)$. 770-788.

Goodwin, J.W., Dunne, J.T., \& Thomas, B.W., (1969). Antepartum identification of the fetus at risk. Canadian Medical Association Journal. 101. 57-67. 
Pregnancy Outcomes

Gottlieb, N.H., \& Green L.W., (1984). Life events, social network, life-style, and health: an analysis of the 1979 national survey of personal health practices and consequences. Health Education Quarterly. $11(1)$. 91-105.

Gravett, M., (1984). (look up in psych-lit for title) Seminars in Perinatology. ㅇ. 246-257.

Haines,V.A., \& Hurlbert,J.S., (1992). Network range and health. Journal of Health and Social Behavior. $33.254-266$.

Hickey, T., Rakowski, W., \& Julius, M., (1988). Preventative health practices among older men and women. Research on Aging. 10(3) 315-328.

Hobel, C.J., Hyvarinen, M., Okada, D., \& Oh, W. , (1973). Prenatal and intrapartum high-risk screening: predictors of the high-risk neonate. American Journal of Obstetrics \& Gynecology. 117. 1-9.

Hobel, C.J., Youkeles, L., \& Forsythe, A., (1979). Prenatal and intrapartum high-risk screening II. Risk factors reassessed. American Journal of Obstetrics \& Gynecology. 135. 1051-1056.

House, J.S., (1981). Work stress and social support. Reading, MA: Addison-Wesley. 
Pregnancy Outcomes

House, J.S., Kessler, R.C., \& Herzog, A.R., (1990) • Age, socioeconomic status and health. The Milbank Quarterly. $\quad \underline{68}(3)$. 383-411.

Jung, J., (1990) . Global versus health-specific social support and match of preferred and perceived social support levels in relationship to compliance and blood pressure of hypertensives. Journal of Applied Social Psychology. 20 (13) . 1103-1111.

Kanner, A.D., Coyne, J., Schaefer, C. \& Lazarus, R., (1981). Comparison of two modes of stress management: daily hassles and uplifts versus major life events. Journal of Behavioral Medicine. $\underline{4}(1)$. 1-39.

Kitagawa, E.M., \& Hauser, P.M., (1973). Differential Mortality in the United States: A Study in Socioeconomic Epidemiology. Cambridge: Harvard University Press.

Kronenfeld, J.J., Goodyear, N., Pate, R., Blair, A., Howe, H., Parker, G., \& Blair S.N., (1988). The interrelationship among preventative health habits. Health Education Quarterly. $\underline{3}(3)$. 317-323. Lederman, R.P., (1995). Relationship of anxiety, stress, and psychosocial development to reproductive health. Behavioral Medicine. 21(3). 101-112. 
Lia-Hoagberg, B., Rode, P., Skovholt, C.J., Oberg, C.N., Berg, C., Mullett, S., \& Choi, T., (1990). Barriers and motivators to prenatal care among lowincome women. Social Science and Medicine. 30(4). 487-495.

McLeod, J.D., \& Kessler, R.C., (1990). Socioeconomic status differences in vulnerability to undesirable life events. Journal of Health and Social Behavior. $31(6)$. 162-172.

Meachen, S.E., \& Kelley, S.D.M., (1991). Special issues in prenatal care outreach. Journal of Health and Social Policy. $\underline{2}(3)$. 53-67.

Moore, K.A., (1988) Facts at a glance. Child Trends Inc.. Charles Stewart Mott Foundation, Flint Michigan.

Muhlenkamp, A.F., \& Sayles, J.A., (1986). Selfesteem, social support, and positive health practices. Nursing Research. 35(6). 334-338.

Naeye, R.L., (1981). Teenaged and pre-teenaged pregnancies: consequences of the fetal-maternal competition for nutrients. Pediatrics. 67(1) . 146150 . 
Norbeck, J.S., \& Anderson, N.J., (1989).

Psychosocial predictors of pregnancy outcomes in lowincome, Black, Hispanic and White women. Nursing Research. 38. 204-209.

Norbeck, J., \& Tilden V. (1983). Life stress, social support, and emotional disequilibrium in complications of pregnancy: a prospective, multivariate study. Journal of Health and Social Behavior. 24. 30-46.

O'Brien, K., Wortman, C.B., Kessler, R.C., \& Joseph, J.G., (1993). Social relationships of men at risk for AIDS. Social Science and Medicine. 36(9). 1161-1167.

Oregon 1990 Census of Population: Social and Economic Characteristics.

Oregon Vital Statistics Report, Volume 1:

Natality, Induced Terminations of Pregnancy \& Teen Pregnancy. (1994).

Pagel, M.D., Smilkstein, G., Regin, H., \& Montano, D., (1990). Psychosocial influences of new born outcomes: a controlled prospective study. Social Science and Medicine. $30(5)$. 597-604. 
Pappas, G., Queen, S., Hadden, W., \& Fisher, G., (1993). The increasing disparity in mortality between socioeconomic groups in the United States, 1960 and 1986. The New England Journal of Medicine. $329(2)$. 103-109.

Parker, K.D., Weaver, G., \& Calhoun, T., (1995). Predictors of alcohol and drug use: a multi-ethnic comparison. Journal of Social Psychology. $135(5)$. $581-590$

Pearlin, L.I., Lieberman, M.A., Menaghan, E.G., \& Mullen, J.T., (1981). The stress process. Journal of Health and Social Behaviors. $\underline{22}(12)$. 337-356. Philpot, V.D., Holliman, W.B., \& Madonna, S.Jr., (1995). Self-statements, locus of control, and depression in predicting self-esteem. Psychological Reports. $\quad$ 76 (3). 1007-1010.

Piechowski, L.D., (1992). Mental health and women's multiple roles. Families in society: The Journal of Contemporary Human Services. $\underline{73}(3)$ - 131139.

Pill, R., Peters, T.J., \& Robling, M.R., (1993). Factors associated with health behavior among mothers of lower socioeconomic status: A British example. Social Science and Medicine. 36(9) . 1137-1144. 
Poole, D.L., \& Carlton, T.O., (1986). A model for analyzing utilization of maternal and child health services. Health and Social Work. 11(3). 209-222.

Public Health Service Expert Panel on the Content of Prenatal Care (1989). PHS Department of Health and Human Services.

Rakowski, W.R., (1988). Age cohorts and personal health behavior in adulthood. Research on Aging. $\underline{10}(1)$. 3-35.

Rosenberg, M., (1979). Conceiving the Self. New York, Basic Books.

Sarason, I.G., Johnson, J.H., \& Siegel, J.M., (1978). Assessing the impact of life changes: development of the life experiences survey. Journal of Consulting and Clinical Psychology. 46. 932-946.

Scheier, M.F., \& Carver, C.S., (1992). Effects of optimism on psychological and physical well-being: theoretical overview and empiracle update. Cognitive Therapy and Research. 16(2). 201-228.

Sheeran, P., \& McCarthy E., (1992). Social structure, self-conception and well-being: an examination of four models with unemployed people. Journal of Applied Social Psychology. 22 (2). 117-133. 
Pregnancy Outcomes

Sherbourne C.D., \& Hays, R.D., (1990). Marital status, social support and health transitions in chronic disease patients. Journal of Health and Social Behavior. $31(12) \cdot 328-343$.

Shumaker, S.A., \& Hill, D.R., (1991). Gender differences in social support and physical health. Health Psychology. 10(2). 102-111.

Tiedje, L.B., Kingry, M.J., \& Stommel, M., (1992). Patient attitudes concerning health behaviors during pregnancy: initial development of a questionnaire. Health Education Quarterly. $19(4) .481-493$.

Turner, J.B., Kessler, R.C., \& House, J.S., (1991). Factors facilitating adjustment to unemployment: implications for intervention. American Journal of Community Psychology. 19(4). 521-542.

Uchino, B.N., Cacioppo, J.T., \& Kiecolt-Glaser, J.K., (1996). The relationship between social support and physiological processes: a review with emphasis on underlying mechanisms and implications for health. Psychological Bulletin. 119(3). 488-531.

Ulbrich, P.M., Warheit, G.J., \& Zimmerman, R.S., (1989). Race, socioeconomic status, and psychological distress: an examination of differential vulnerability. Journal of Health and Social Behavior. 30(3). 131-146. 
Pregnancy Outcomes

Umberson, D., (1987). Family status and health behaviors: social control as a dimension of social integration. Journal of health and Social Behavior. $\underline{28}(9) \cdot 306-319$.

Verbrugge, L.M., (1989). The twain meet: empiracle explanations of sex differences in health and mortality. Journal of health and Social Behavior. $\underline{30}(9)$. $282-304$.

Wall, E.M., Sinclair, A.E., Nelson, J.\& Toffler, W.L., (1989). The relationship between assessed obstetric risk and maternal-perinatal outcome. Journal of Family Practice. $\quad \underline{28}(1) \cdot 25-40$.

Weinman, M.L., (1990). Sociodemographic and maternal behaviors in younger and older pregnant adolescents. Child and Adolescent Social Work. I (1). 43-52.

Wiebe, D.J., \& Williams, P.G., (1992). Hardiness and health: a social psychophysiological perspective on stress and adaptation. Journal of Social and Clinical Psychology. $11(3)$. 238-262.

Williams, D.R., (1990). Socioeconomic differentials in health: a review and redirection. Social Psychology Quarterly. 픈 (2) 81-99. 
Yeager, K.K., Macera., C.A., \& Merritt, R.K., (1993). Socioeconomic influences on Leisure-time sedentary behavior among women. Health Values: The Journal of health Behavior-Education and Promotion. $\underline{17}(6)$. $50-54$ Zimmer-Gembeck, M., \& Helfand, M., (1996). Low birthweight in a public prenatal care program: behavioral and psychosocial risk factors and psychosocial intervention. Social science and Medicine. $\quad \underline{43}(2)$. 187-197. 
Appendix A

Time 1 Data Collection 


Sociodemographic Survey

A1. Today's Date $\frac{}{\text { Mo }} ' \overline{\text { Day }} / \overline{\text { Year }}$

A2. Date of Birth $\frac{}{\text { Mo }} / \frac{}{\text { Day }} / \overline{\text { Year }}$

A3. What is your current partner status? Are you (read choices):
$\square \quad$ 1. Married living with your parther
$\square \quad 2$ Married living alone
$\square \quad 3$. Single living with your partiner
$\square$ 4. Singie living alone

A4. How many years of education have you completed? (GED $=12$ years)

A5. Did you drop out of high sciool?
$\square \quad$ 0. No
$\square$ 1. Yes

A6. What is your ace?
ㄱ. Cáucasian
- 2 African American
$\square$ 3. Native American
4. Hispanic
ㄱ. Asian
$\square \quad$ 6. Other (please specify)

A7. What is your total family income each month?

A.8. How many people currently reside in your your housenoid?

A. Do you work outsilie the home?
0. No (Go to question A13)
$\square \quad$ 1. Yes (Go to question A10) 


Sociodemographic Survey $\quad$ Study ID\#

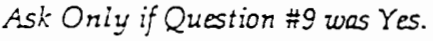

A10. Does the work involve heavy, physical labor?

$\begin{array}{ll}\square & \text { 0. No } \\ \square & \text { 1. Yes }\end{array}$

Ai1. Is the work stressful?
0. No
1. Yes

A12 Do you have to commute more than 30 minutes one way to work?

$\begin{array}{ll}\square & \text { 0. No } \\ \square & \text { 1. Yes }\end{array}$

A:3. How many tines have you been pregnant, including this pregnancy?

A14. Fow many times have you given birth, induding any still born births?

A:E. Fow far aiong are you tociay? (in weeks) (Lifestyle Behavioral Risk Factor)

(If not sure, complete after exam)

Ai6. Fave you had any prenatal care for this pregnancy prior to today's visit?

o. No

1. Yes (if yes, record dates and number of oisits)

Ai7. Was this pregnancy plannei?

$\begin{array}{ll}\square & \text { 0. No } \\ \square & \text { 1. Yei: } \\ \square & 2 \text { Ye: and No (please explain) }\end{array}$


Pregnanay Outcomes

\begin{tabular}{|c|c|c|c|c|}
\hline \multicolumn{3}{|c|}{ Psychosocial Assessment Tool } & \multicolumn{2}{|l|}{ Study $\mathbb{D D}^{*}$} \\
\hline \multicolumn{5}{|l|}{$\begin{array}{l}\text { Assessment or Stress } \\
\text { Ask women to wnat extent the following factors are current } \\
\text { stressors/hassles. Circle the number correspording to the } \\
\text { appropriate response. }\end{array}$} \\
\hline $\begin{array}{l}\text { To what extent are (READ CHOICE) a current stressor/ } \\
\text { hassle for you? }\end{array}$ & $\begin{array}{c}\text { No } \\
\text { Stress } \\
1\end{array}$ & $\begin{array}{c}\text { Some } \\
\text { Stress } \\
2\end{array}$ & $\begin{array}{c}\text { Moderate } \\
\text { Stress } \\
3\end{array}$ & $\begin{array}{c}\text { Severe } \\
\text { Stess } \\
4\end{array}$ \\
\hline $\begin{array}{l}\text { A18A. Financial worries (e.g., food, shelter, health care, } \\
\text { transportation) }\end{array}$ & 1 & 2 & 3 & 4 \\
\hline A18B. Other money worries (e.g., biils, etc) & 1 & 2 & 3 & 4 \\
\hline A18C. Problems related to family (parner, children, etc) & 1 & 2 & 3 & $\leq$ \\
\hline A18D. Having to move, either recently or in the furure. & 1 & 2 & 3 & 4 \\
\hline A.18E. Recent loss of a loved one & 1 & 2 & 3 & 4 \\
\hline AisF. Current pregnancy & 1 & 2 & 3 & 4 \\
\hline A18G. Current abuse, sexual, emotional, or physical & 1 & 2 & 3 & 4 \\
\hline A18II Problems with alcohol and/or cirigs & 1 & 2 & 3 & 4 \\
\hline A18I. Work problems (e.g., being laic off, etc) & 1 & 2 & 3 & 4 \\
\hline A.18J. Problems related to friencis & $i$ & 2 & 3 & 4 \\
\hline A18K. Feeling generally "overioaded" & I & 2 & 3 & 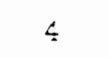 \\
\hline
\end{tabular}




\section{Pregnancy Outcomes}

Psychosocial Assessment Tool Study ID\#_

Assessment of Support

This next set of questions asks how satisfied you are with the amount of support you receive from your partner and/or other people.

A19. First of all, do you have a partner?

$$
\begin{array}{lll}
\square & 0 . & \text { No (ask only about support from others) } \\
\square & \text { 1. Yes. }
\end{array}
$$

I will read you a list of statements describing types of support. On a scale of 1 to 6 , with 1 being very dissatisfied and 6 being very satisfied, I want you to tell me how satisfied you are with the support you receive from (your partiner/other people).

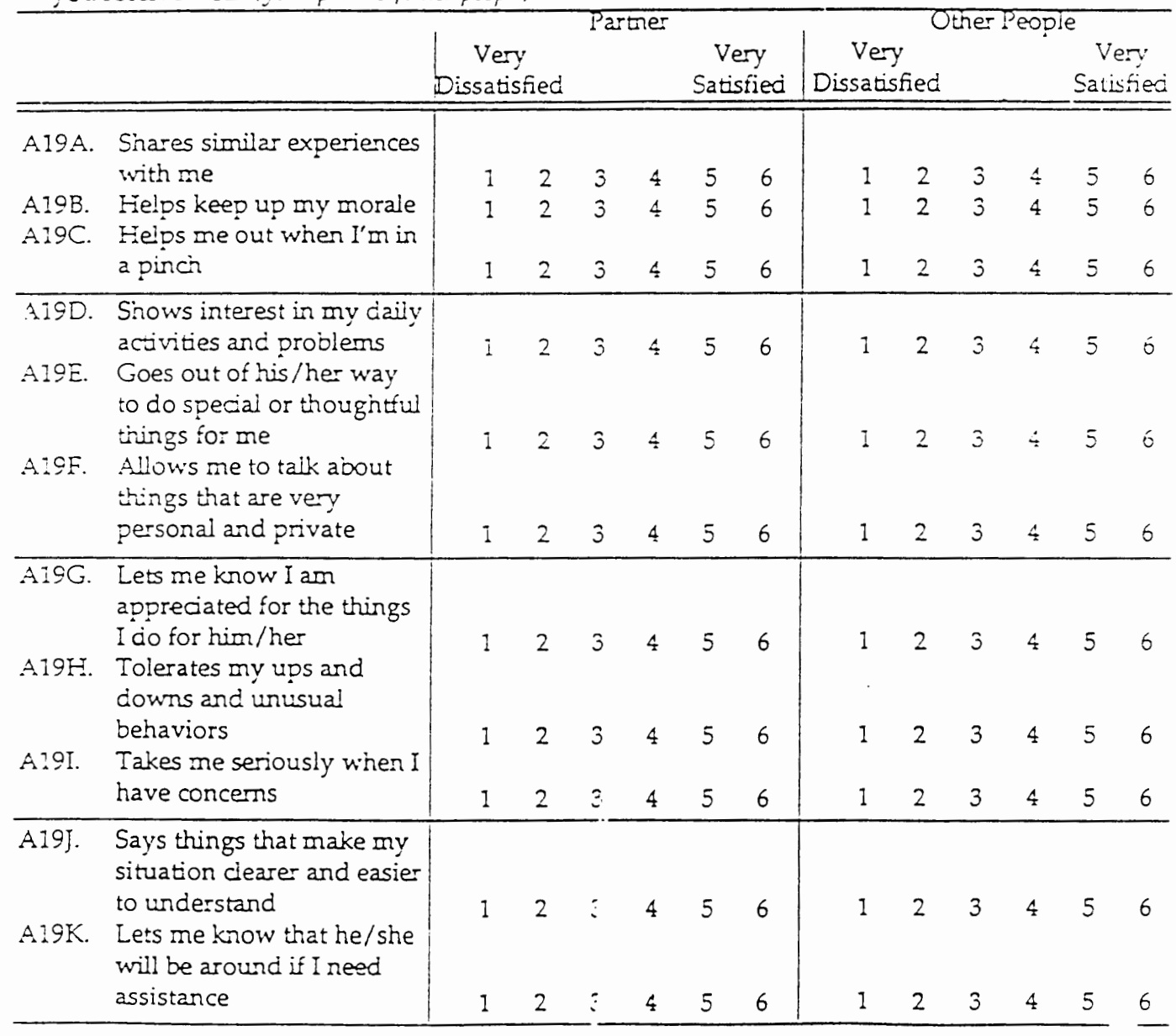

If respondent has partner: Now I will reac these statements again, and I want you to tell me how sait:siec you are with the support you receive from people other than your partner. 
Pregnancy Outcomes

Psychosocial Assessment Tool Study ID\#__

\section{Assessmert of Self Esteem}

We all have some kind of "picture" of ourseives we carry with us. I'm going to read you a list of statements that people have used to describe themselves. I would like you to tell me how much you agree or disagree that this statement describes yourseif.

\begin{tabular}{|c|c|c|c|c|c|}
\hline & . & $\begin{array}{l}\text { Strongly } \\
\text { Agree }\end{array}$ & Agree & Disagree & $\begin{array}{l}\text { Strongly } \\
\text { Disagree }\end{array}$ \\
\hline$A 20 \mathrm{~A}$ & $\begin{array}{l}\text { Feel that you're a person of worth, at } \\
\text { least on an equal basis with others. }\end{array}$ & 1 & 2 & 3 & 4 \\
\hline$A 20 B$ & $\begin{array}{l}\text { Feel that you have a number of good } \\
\text { quaities. }\end{array}$ & 1 & 2 & 3 & 4 \\
\hline $\mathrm{A} 20 \mathrm{C}$ & All in ail, feel that you are a failure. & i & 2 & 3 & 4 \\
\hline$A 200$. & $\begin{array}{l}\text { Feel you are able to do things as well as } \\
\text { most other people. }\end{array}$ & 1 & 2 & 3 & 4 \\
\hline$A 20 E$ & $\begin{array}{l}\text { Feel you do not have much to be proud } \\
\text { of. }\end{array}$ & 1 & 2 & 3 & 4 \\
\hline $\mathrm{A} 20 \mathrm{E}$ & Take a positive attitude towarc yourseif. & 1 & 2 & 3 & 4 \\
\hline$\therefore 20 C$ & $\begin{array}{l}\text { On the whole, feei satisfied with } \\
\text { yourself. }\end{array}$ & 1 & 2 & 3 & 4 \\
\hline$A=0 F$ & $\begin{array}{l}\text { Wish you could have more respect for } \\
\text { yourself. }\end{array}$ & $i$ & 2 & 3 & 4 \\
\hline A2OI. & Feel useless at tines. & 1 & 2 & 3 & 4 \\
\hline$A=0 J$ & At times thirk you are no good at all. & 1 & 2 & 3 & 4 \\
\hline A.2OK. & Fell like you have control over your life. & 1 & 2 & 3 & 4 \\
\hline
\end{tabular}

A20L. Did this interview bring up any concerns or questions that you would like to discuss with your prenatal care provider?

$$
\square \text { 0. No }
$$

A20M. Would you like me to approach your prenatal care provider with this concern or question for you?

$$
\square \begin{array}{ll}
\square . & \text { No } \\
\square & \text { 1. Yes }
\end{array}
$$




\section{Pregnancy Outcomes}

\section{Lifestyle and Habits Survey Study ID*}

These questions ask about your intake of tobacco, alcohol, and drugs. Remember, yours answers are confidential and will not go into your medical record or be released.

A21. How much do you smoke these days?

$\square$ 0. None

1. 1 - 9 cigarettes a day

$\square$ 2. 10 - 20 cigarettes a day

3. more than a pack a day

A22 Eow much marijuara do you use these days?
7 0. None
7 1. less than $\mathrm{i}$ joint a week
- 2 I-5 joints a week
3. $6-10$ joints a week
A. more than 10 joints a week

A23. Fow much beer, wine, or hard liquor do you dirin these days?

(NOTE: cre cunce = one beer = one dirirk = one glass of wine)
0. None
1. Less than i ounce a day
21 ounce a ciay
3. 2 ounces a diay
4. 3 ounces a diy
5. More than 3 ounces a day

A24. How often do you use hard dnigs (cocaine, heroin, speed, etc) these days?

0 . Never

$\square$ 1. Less than once a week

$\square \quad 21$ - 3 tines a week

7. 4-6 times a week

7 4. More than 6 times a week 
Pregnancy Outcomes

131

Chart Audit $\quad$ Study ID\#_L

Initial Biomedical Risk Tool

Circle "Yes" for each risk factor noted in the chart.

\begin{tabular}{|c|c|c|}
\hline & No & Yes \\
\hline A.34A. & First visit $>20$ weeks or unsure dates & 1 \\
\hline $\mathrm{A} 34 \mathrm{~B}$ & Mothers weight $<100$ pounds or $>200$ pounds & 1 \\
\hline A.34C. & Mother's height $<5$ feet & 1 \\
\hline A34D. & 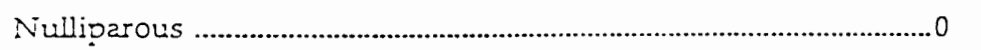 & 1 \\
\hline A.34E. & Parity $>5$ & 1 \\
\hline A.34F. & 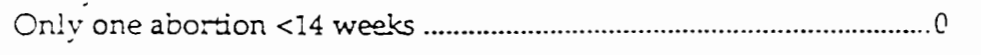 & 1 \\
\hline$A 34 G$ & Two abortions $<14$ weeks & $\cdot 1$ \\
\hline A34F. & 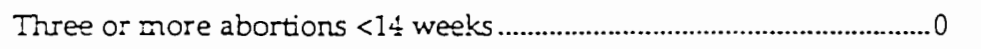 & 1 \\
\hline A34I. & One second trimester abortion (spontaneous) ......................................... 0 & 1 \\
\hline A.34J. & 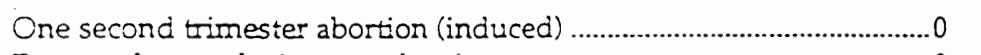 & 1 \\
\hline A.34K. & Repeated second trimester abortion & 1 \\
\hline A.34L. & 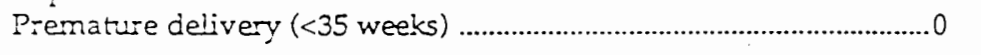 & 1 \\
\hline$A 34 \mathrm{M}$ & Growti retarded infant (IUGR) & 1 \\
\hline$A=4$ Ni. & Infant >10 pounds & 1 \\
\hline A34O. & $<1$ year since last birth to LMP & 1 \\
\hline A.34P. & 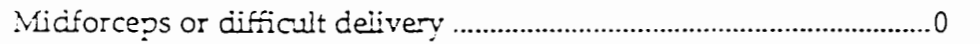 & 1 \\
\hline$A 3 \div Q$ & 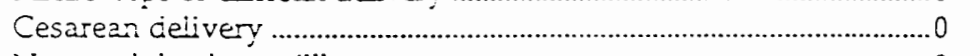 & $?$ \\
\hline$A \omega \leq R$ & 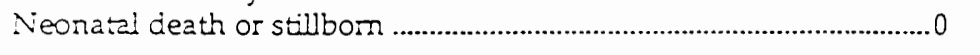 & 1 \\
\hline$A 34 S$ & 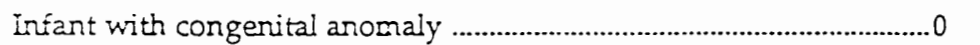 & 1 \\
\hline A34T. & Arte or postpartum hemorhage & 1 \\
\hline A34U. & Edampsia or severe pregnancy induced hypertension .......................... 0 & 1 \\
\hline $\mathrm{A} .34 \mathrm{~V}$ & 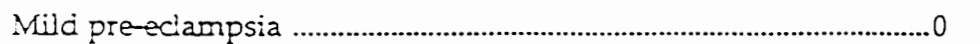 & 1 \\
\hline$A 34 W$. & Isoimmunization (e.g., Rh) & 1 \\
\hline A. $34 X$ & DES exposure & 1 \\
\hline A.34Y. & Herpes & 1 \\
\hline A.34Z & 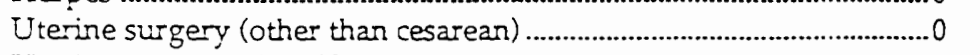 & 1 \\
\hline A.34AA. & Uterine or cervical malformation & 1 \\
\hline
\end{tabular}

Proceer to next page. 
Pregnancy Outcomes

132

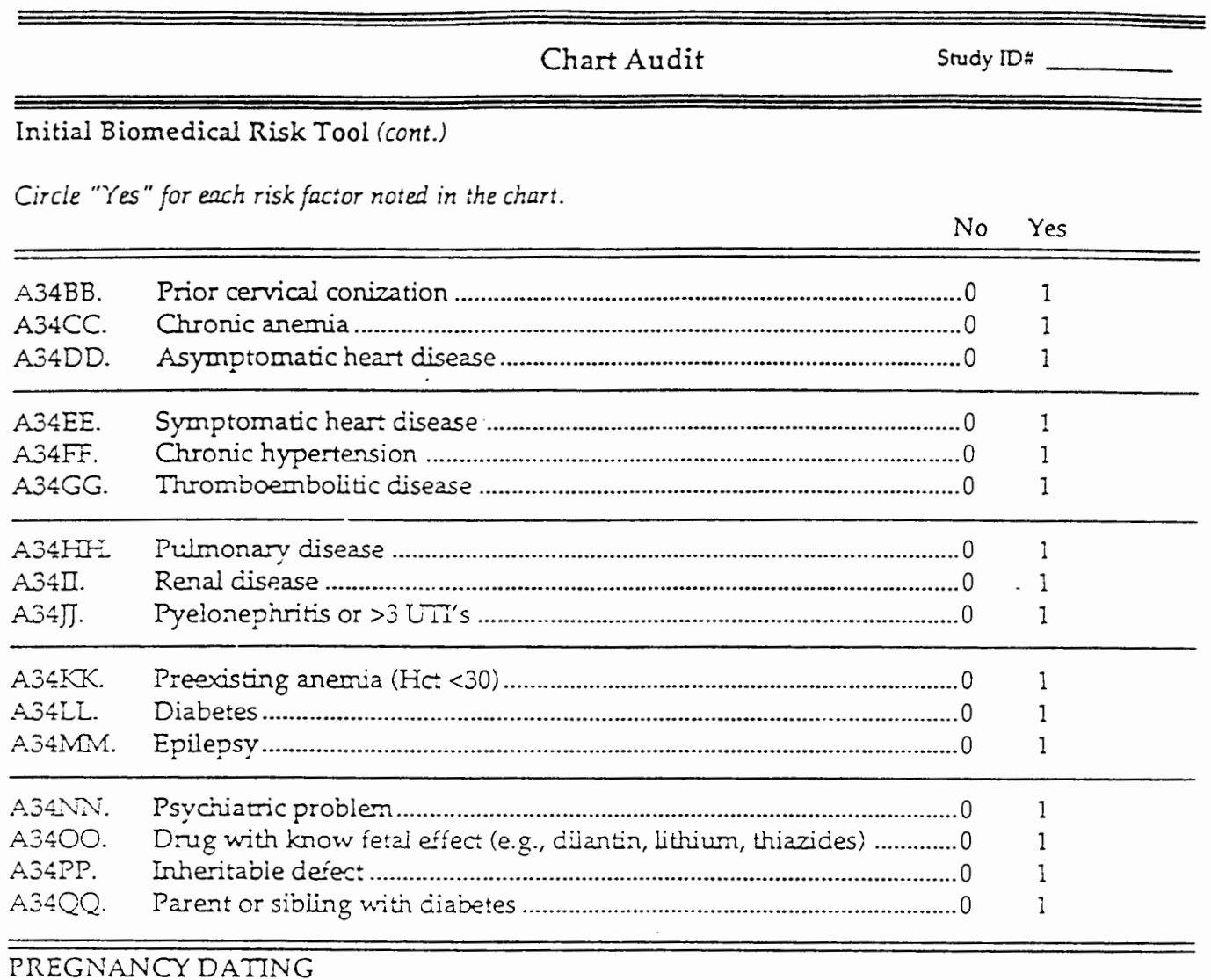

Weeks gestation at this visit 
Appendix B

Time 2 Data Collection 
Pregnancy Outcomes

Psychosocial Assessment Tool

Study ID\#

\section{Assessment of Stress}

Ask women to what extent the following factors are curtent stressors/hassles. Circle the number corresponding to the appropriate response.

\begin{tabular}{|c|c|c|c|c|}
\hline $\begin{array}{l}\text { To what extent are (READ CHOICE) a curient stressor/ } \\
\text { hassle for you? }\end{array}$ & $\begin{array}{l}\text { No } \\
\text { Stress } \\
\quad 1\end{array}$ & $\begin{array}{l}\text { Some } \\
\text { Stress } \\
2\end{array}$ & $\begin{array}{l}\text { Moderate } \\
\text { Stress } \\
\quad 3\end{array}$ & $\begin{array}{l}\text { Severe } \\
\text { Stress } \\
4\end{array}$ \\
\hline $\begin{array}{l}\text { B18A. Financial worries (e.g., food, shelter, health care, } \\
\text { transportation) }\end{array}$ & 1 & 2 & 3 & 4 \\
\hline BiSB. Other money worries (e.g., biils, etc) & 1 & 2 & 3 & 4 \\
\hline B18C. Problems related to family (parner, chilciren, etc) & 1 & 2 & 3 & 4 \\
\hline B18D. Having to move, either recently or in the future. & 1 & 2 & 3 & 4 \\
\hline BISE. Recent loss of a loved one & 1 & 2 & 3 & 4 \\
\hline B18F. Curient pregnancy & ] & 2 & 3 & 4 \\
\hline Bi8G. Curent abuse, sexual, emotionai, or pinysical & i & 2 & 3 & 4 \\
\hline B18H Problems with alconol and/or drugs & 1 & 2 & 3 & 4 \\
\hline B181. Work problens (e.g., being laid off, etc) & 1 & 2 & 3 & 4 \\
\hline B181. Problems related to friends & 1 & 2 & 3 & 4 \\
\hline BisK. Feeiling generaily "overioaded" & 1 & 2 & 3 & 4 \\
\hline
\end{tabular}


Pregnancy Outcomes

Psychosocial Assessment Tool $\quad$ Study ID\#___

Assessment of Support

This next set of questions asks how satisfied you are with the amount of support you receive from your partiner and/or other people.

Bi9. First of all, do you have a partner?

0 . No (ask only about support from others)

1. Yes.

I will read you a list of statements describing types of support. On a scale of 1 to 6 , with I being very dissatisfied and 6 being very satisfied, I want you to tell me how satisfied you are with the support you receive from (your partner/other people).

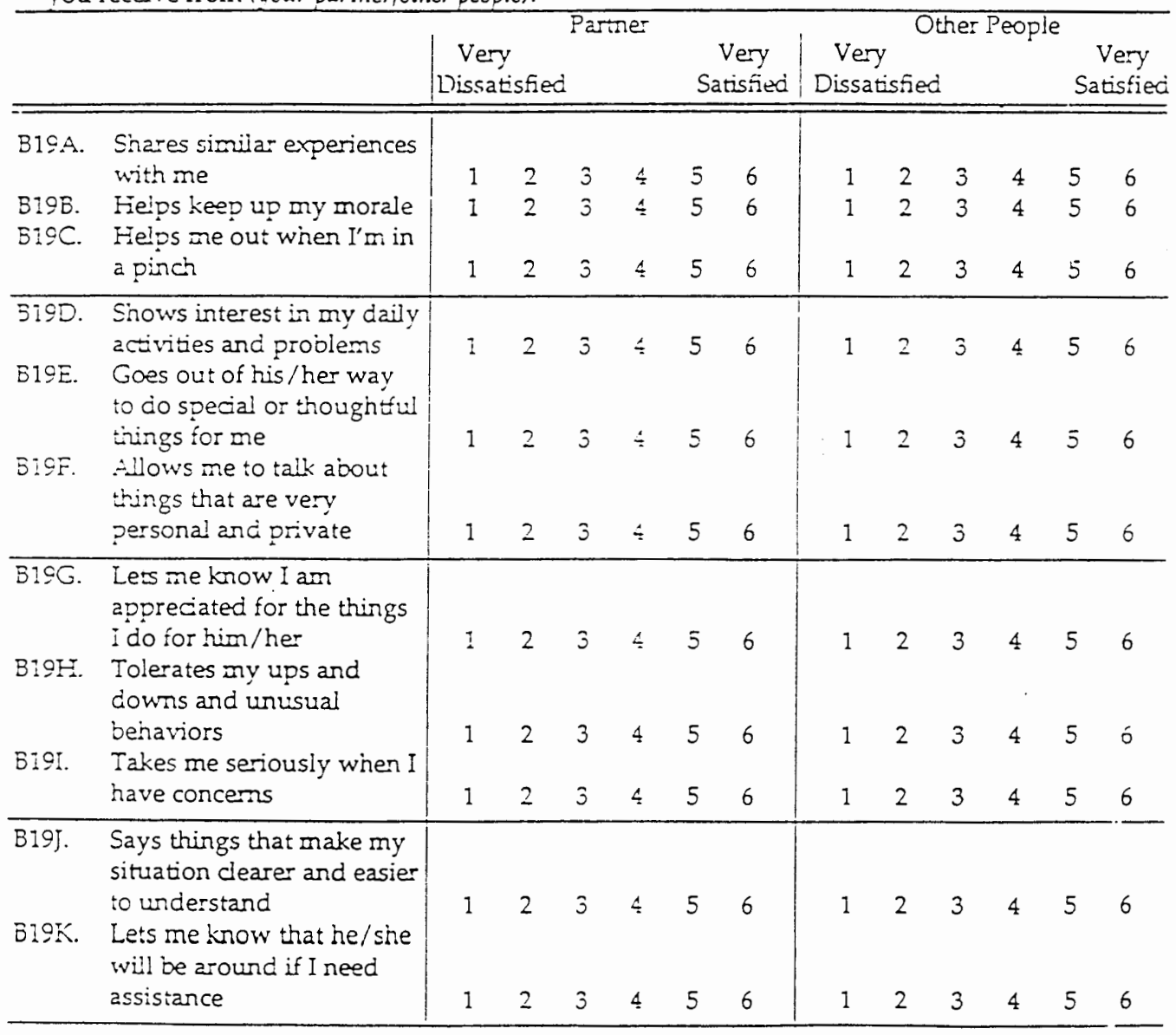

If respondent has partner: Now I will read these statements again, and I want you to tell me how satisied you are with the support you receive from people other than your partner.

$$
\therefore 10
$$


Pregnancy Outcomes

\section{Psychosocial Assessment Tool}

Study $\mathbb{D} \#$

\section{Assessment of Self Esteem}

We all have some kind of "picture" of ourselves we carry with us. I'm going to read you a list of statements that people have used to describe themselves. I would like you to tell me how much you agree or disagree that this statement describes yourself.

\begin{tabular}{|c|c|c|c|c|c|}
\hline & & $\begin{array}{l}\text { Strongly } \\
\text { Agree }\end{array}$ & Agree & Disagree & $\begin{array}{l}\text { Strongly } \\
\text { Disagree }\end{array}$ \\
\hline B20.A. & $\begin{array}{l}\text { Feel that you're a person of worth, at } \\
\text { least on an equal basis with others. }\end{array}$ & 1 & 2 & 3 & 4 \\
\hline B 208 & $\begin{array}{l}\text { Feel that you have a number of good } \\
\text { cuaitities. }\end{array}$ & I & 2 & 3 & 4 \\
\hline B20C. & All in all, feel that you are a failure. & 1 & 2 & 3 & 4 \\
\hline BZOD. & $\begin{array}{l}\text { Feel you are able to co things as well as } \\
\text { most other people. }\end{array}$ & 1 & 2 & 3 & 4 \\
\hline B20E. & $\begin{array}{l}\text { Feel you do not have much to be proud } \\
\text { of. }\end{array}$ & 1 & 2 & 3 & 4 \\
\hline$B 20=$ & Take a positive attitude towarc yourself. & 1 & 2 & 3 & 4 \\
\hline B20G. & $\begin{array}{l}\text { On the whole, feel satisfied with } \\
\text { yourself. }\end{array}$ & 1 & 2 & 3 & 4 \\
\hline B205. & $\begin{array}{l}\text { Wish you could have more respect for } \\
\text { yourseif. }\end{array}$ & 1 & 2 & 3 & 4 \\
\hline B2OI. & Feel useless at times. & 1 & 2 & 3 & 4 \\
\hline B2OJ. & At times think you are no good at all. & 1 & 2 & 3 & 4 \\
\hline B20K. & Feei like you have control over your life. & 1 & 2 & 3 & 4 \\
\hline
\end{tabular}

B20L. Did this interview bring up any concerns or questions that you would like to discuss with youprenatai care provider?

$$
\begin{array}{ll}
\square & 0 . \text { No } \\
\square & \text { 1. Yes }
\end{array}
$$

B20M. Would you like me to approach your prenatal care provider with this concern or question for you?

$$
\begin{aligned}
& \square \\
& \square \\
& \text { 1. No Nos }
\end{aligned}
$$




\section{Pregnancy Outcomes}

These questions ask about your intake of tobacco, alcohol, and drugs and whether you are receiving WIC food vouchers. Remember, yours answers are confidential and will not go into your medical record or be released.

B21. How much do you smoke these days?

$\square$ 0. None

1. 1 - 9 cigarettes a day

$\square 2$ 10-20 cigarettes a day

3. more than a pack a day

B22. How much marijuana do you use these days?
0. None
1. less than 1 joint a week
$\square \quad 2$ 1- 5 joints a week
7] 6 - 10 joints a week
$\square$ 4. more than 10 joints a week

B23. How much beer, wine, or hard liquor do you dink these days?

(NOTE: one ounce $=$ one beer $=$ one drink $=$ one gless of wine)
๑ 0. None
1. Less than 1 ounce a ciay
2 2. 1 ounce a day
$\square$ 3. 2 ounces a day
4. 3 ounces a day
$\square$ 5. More than 3 ources a day

B24. How often do you use hard drugs (cocaine, heroin, speed, etc) these days?

$\square$ 0. Never

$\square$ 1. Less than once a week

$\square \quad 2$ 1-3 times a week

$\square$ 3. 4-6 times a week

$\square$ 4. More than 6 times a week 
Pregnancy Outcomes

Chart Audit $\quad$ Study ID\#\#

Second Trimester Biomedicai Risk Tool

Circle "Yes" for each risk factor noted in the chart.

\begin{tabular}{|c|c|c|}
\hline $\begin{array}{l}\text { B34A. } \\
\text { B34B. } \\
\text { B34C. }\end{array}$ & 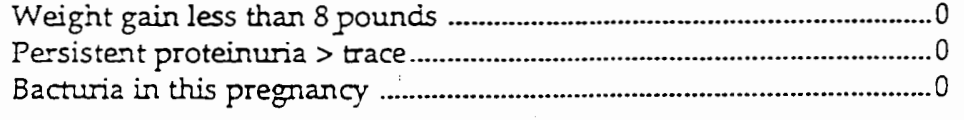 & $\begin{array}{l}1 \\
1 \\
1\end{array}$ \\
\hline $\begin{array}{l}\text { B34D. } \\
\text { B34E. } \\
\text { B34F. }\end{array}$ & 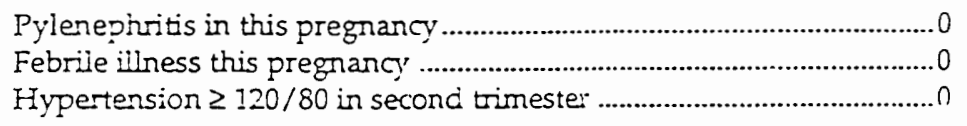 & $\begin{array}{l}1 \\
1 \\
1\end{array}$ \\
\hline $\begin{array}{l}\text { B34G. } \\
B 34 \mathrm{H} \text {. } \\
B 34 \mathrm{I}\end{array}$ & 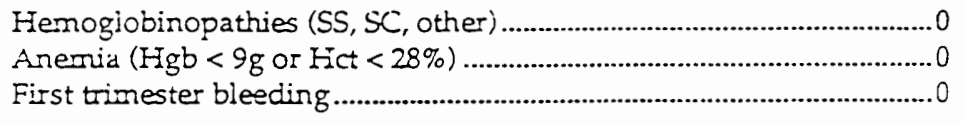 & $\begin{array}{l}1 \\
1 \\
1\end{array}$ \\
\hline $\begin{array}{l}\text { B3AI. } \\
B 3 \leq K \\
B 34 L\end{array}$ & 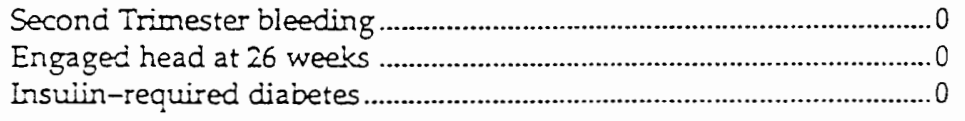 & $\begin{array}{l}1 \\
1 \\
1\end{array}$ \\
\hline 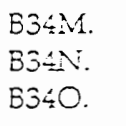 & 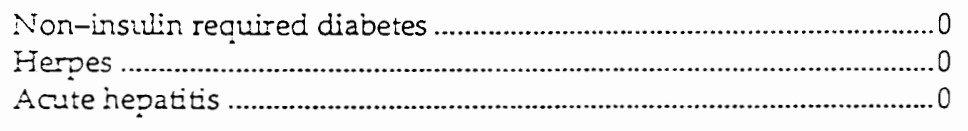 & $\begin{array}{l}1 \\
1 \\
1\end{array}$ \\
\hline $\begin{array}{l}B 34 P \\
B 34 Q \\
B 34 R\end{array}$ & $\begin{array}{l}\text { Syphiiis } \\
\text { Gonortiea } \\
\text { Rubella }\end{array}$ & $\begin{array}{l}1 \\
1 \\
1\end{array}$ \\
\hline $\begin{array}{l}\text { B34S. } \\
\text { B34T. } \\
\text { B34U. }\end{array}$ & $\begin{array}{l}\text { Toxoplasmosis or CMV } \\
\text { Premature labor } \\
\text { Premature rupture of membranes }\end{array}$ & $\begin{array}{l}1 \\
1 \\
1\end{array}$ \\
\hline $\begin{array}{l}B 34 \mathrm{~V} \\
B 34 \mathrm{~W} \\
B 34 X\end{array}$ & $\begin{array}{l}\text { Cerclage } \\
\text { Abnormal initial PAP this pregnancy } \\
\text { IUGR confirmed by ultrasounds }\end{array}$ & $\begin{array}{l}1 \\
1 \\
1\end{array}$ \\
\hline $\begin{array}{l}\text { B34Y. } \\
B 34 Z \text {. } \\
\text { B3A ALA. }\end{array}$ & $\begin{array}{l}\text { Isoimmunization (no transfusion) } \\
\text { Isoimmunization (transfusion required) } \\
\text { Effacement }>20 \% \text { at } 26 \text { weeks }\end{array}$ & $\begin{array}{l}1 \\
1 \\
1\end{array}$ \\
\hline
\end{tabular}

Proceed to next page. 
Pregnancy Outcomes

139

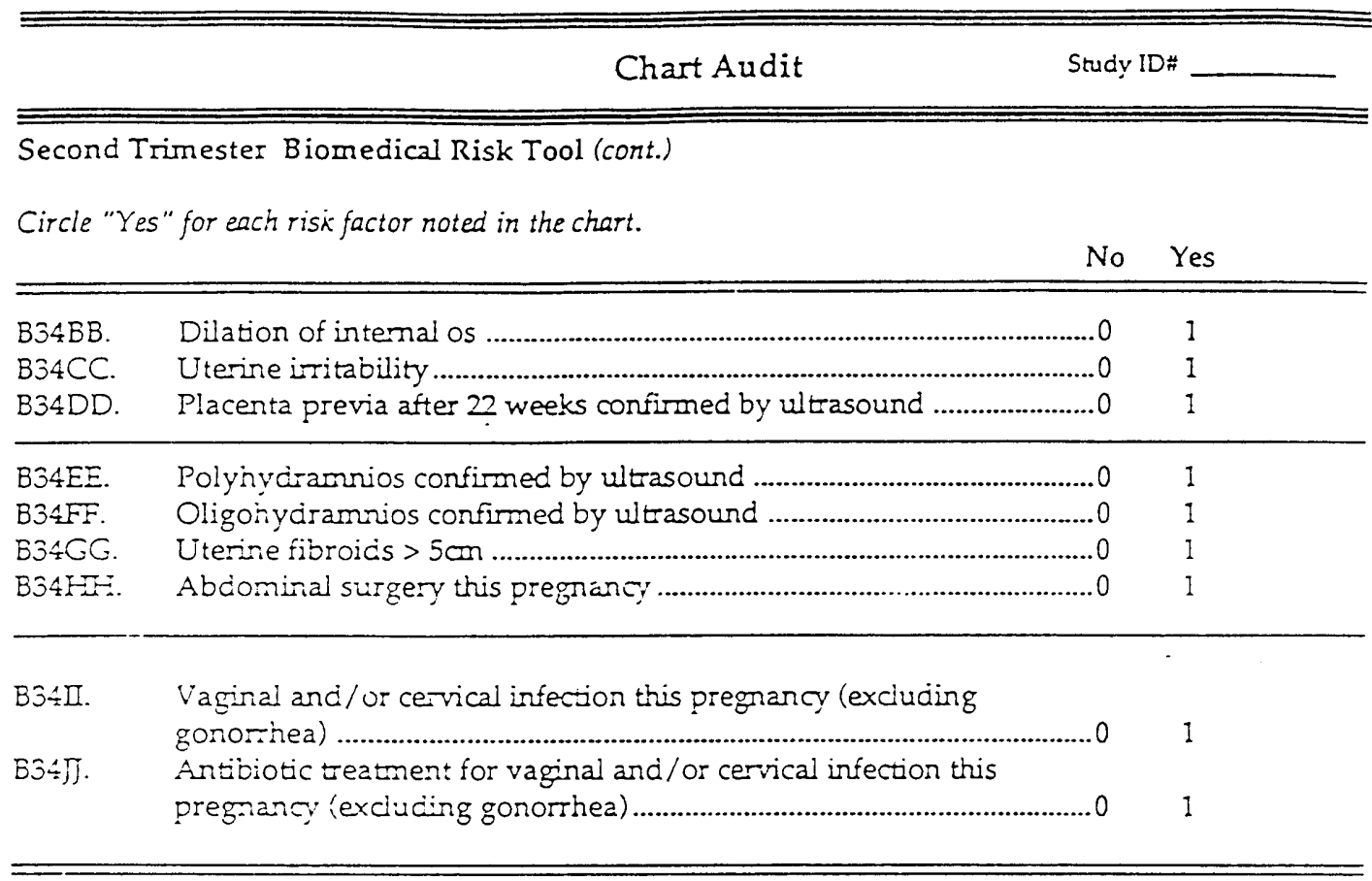


Appendix C

Time 3 Data Collection 
Pregnancy Outcomes

141

At Delivery 2

C35. How many prenatal visits did the subject make during this pregnancy? 
$\equiv$

Outcome Measures

Study $D^{*}$ \#

Infant birthweight

C36. Actual birthweight in grams

C37. Low birthweight ( $\leq 2500$ grams)
$\square$. No
$\square$ 1. Yes

Infant Complications

C38. Actual weeks gestation

C39. Preterm infant $\leq 37$ weeks
$\square \quad 0$. No
$\square$ 1. Yes

C40. Actual one minute Apgar score

C41. One minute Apgar less than 7
$\square$ 0. No
$\square$ 1. Yes

C42 Actual Eve minute Apgar score

$C \div 3$. Five minute Apgar less than 7
7 o. No
$\square$ 1. Yes

C41. Crown/heel length in centimeters

C45. Head arcumference in centimeters

C46. Intrauterine growth retardation
$\square \quad 0$. No
$\square$ 1. Yes

C47. Meconium taining at delivery
[ 0 . No
$\square$ 1. Yes

C48. Adinit/trar:sfer to Neonatal Intensive Care Unit
O 0. No
$7 \quad$ 1. Yes 
Pregnancy Outcomes

143

\section{Outcome Measures Study ID\#}

\section{Labor \& Delivery Complications and Use of Anesthesia \& Analgesia}

C49. Onset of labor spontaneous
$\square \quad$ 0. No (labor spontaneous)
$\square \quad$ 1. Yes (labor induced)

C50. Delivery assisted (vacuum, forceps)
$\square$
0 . No
1. Yes

C51. Cesarean delivery
$\square$
o. No
1. Yes

C\$2 First stage o: labor longer than normal (For primiparas greater than 22.9 hours for first stage; for multiparas greater than 13.1 hours for first stage)
$\square$
0 . No
1. Yes

C53. Seconci stage of labor longer than normal (For primiparas greater than 105 minutes for secona' stage; for milit:pares greater than 32 minutes for second stage)
$\square$
o. No
1. Yes

C34. Epicural ariaigesia
$\square$ 0. No
$\square \quad$ 1. Yes

C55. Narcotic analgesia
$\square$ o. No
1. Yes

C56. Migh blood pressure during labor/delivery ( $>139$ ooer 89 ooer a period of at least 2 hours)
$\square \quad 0$. No
[1. Yes

C57. Membranes ruptured longer than 24 hours before delivery
$\square$ 0. No
$\square$ 1. Yes

C58. Cervical infection on admission to labor
$\square \quad 0$. No
$\square$ 1. Yes 
Pregnancy Outcomes

STATE OF OREGON

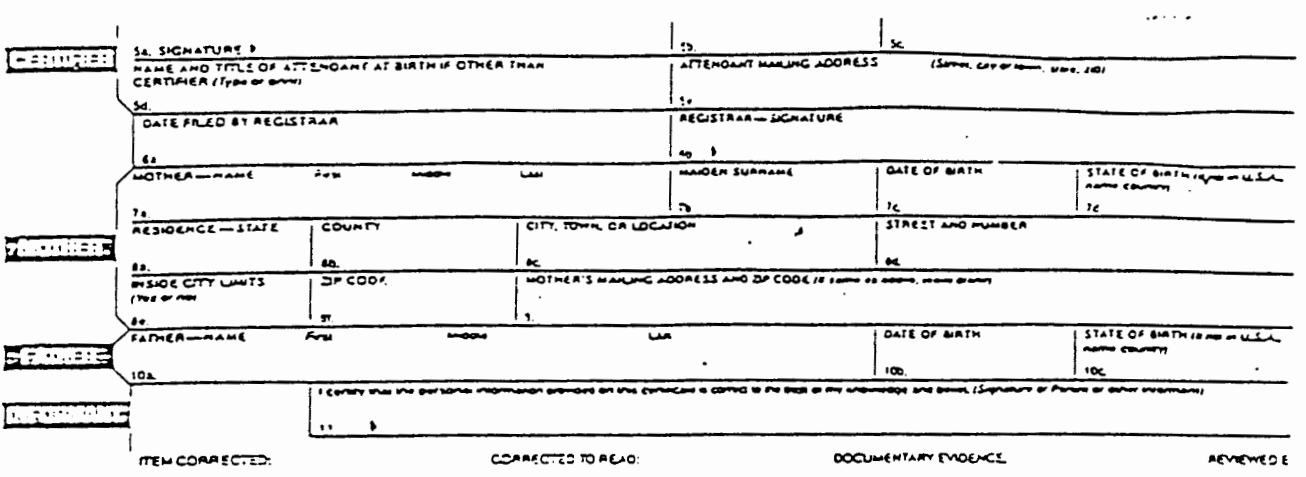

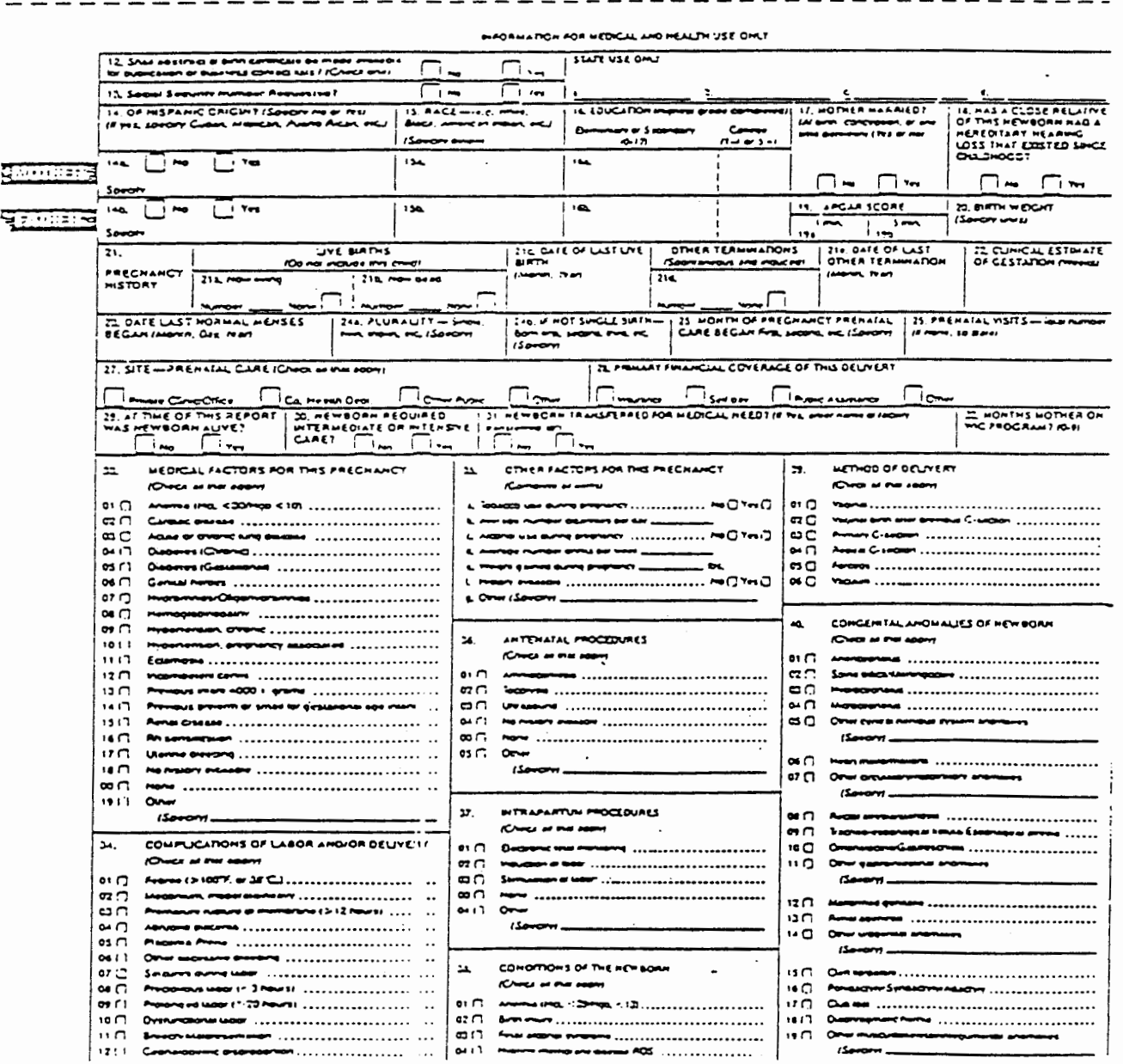

